\title{
Methods for understanding social-ecological systems: a review of place- based studies
}

\author{
${\text { Alta de } \text { Vos }^{1}, \text { Reinette Biggs }^{2,3} \text { and Rika Preiser }}^{2}$
}

\begin{abstract}
In recent years, social-ecological systems (SES) have emerged as a prominent analytical framing with which to investigate pressing sustainability issues associated with the Anthropocene era. Despite the growth of SES research, the lack of a delineated set of methods commonly contributes to disorientation for those entering into a field where methodological pluralism is the norm. We conduct a review of SES research, focusing particularly on methods used in this field. Our results reflect the rapid growth in SES research relative to other publications in relevant subject areas, and suggest a maturation of the field. Whilst institutions investigating SES have been mostly based in the global north, focal SES has been more globally distributed, although key regions, especially island regions, remain poorly studied. Key problems addressed in the studies related to policy, trade, conservation, adaptation, land use change, water, forests, sustainability, urban problems, and governance and institutions. We identified 311 methods, which we grouped into 27 method categories that can serve as a guide to SES research methods for newcomers to the field. We also performed an exploratory assessment of the ability of these methods to account for key features of SES as complex adaptive systems. We found that methods do better at accounting for the relational and context-dependent nature of SES, and least well with complex causality. Our study highlights the plurality of methods used in SES research, and helps highlight key areas in need of further methodological development.
\end{abstract}

Key Words: complex adaptive systems; global change; methodological pluralism; methods; place-based; resilience; social-ecological systems

\section{INTRODUCTION}

Human activities are changing the ecosystems upon which humanity depends in unprecedented and profound ways (Rockström et al. 2009). In the fast-changing and ever-moreconnected era of the Anthropocene (Rockström et al. 2009, Steffen et al. 2011), the environmental and social challenges we face demand better understanding of the complex and evolving links between ecosystems and human societies (Rockström et al. 2009, Fischer et al. 2015). The concept of social-ecological systems (SES) has emerged as a key conceptual and analytical framing with which to understand the connections and feedbacks between social and environmental interactions in real-world systems (Carpenter et al. 2012, Fischer et al. 2015, Colding and Barthel 2019). The concept has helped facilitate increased recognition of the dependence of humanity on ecosystems (Díaz et al. 2006, Summers et al. 2012, Wu 2013), has improved collaboration across disciplines and between science and society (Carpenter et al. 2012), has increased methodological pluralism that has led to improved systems understanding (Levin et al. 2013, Tengö et al. 2014, Lade and Niiranen 2017, Preiser et al. 2018), and has manifested in major policy frameworks and initiatives, such as Future Earth (Rockström 2016) and the Sustainable Development Goals (Díazet al. 2015a, Fischer et al. 2015). Recent years have also seen the emergence of new research areas (Folke 2006), modeling approaches (Schlüter et al. 2012), and analytic frameworks (Turner et al. 2003, Janssen et al. 2006, Collins et al. 2011, Bodin and Tengö 2012, Schlüter et al. 2019).

Despite progress, SES research remains challenging (Fischer et al. 2015, Turner et al. 2016, Haider et al. 2018). Central to this challenge is the recognition that SES research represents an emergent "third" space that transcends the mere sum of social and ecological research practices and disciplines (Walker et al. 2006, Liu et al. 2007a, Folke et al. 2016). Many methods and approaches used in SES research do not fall within the realms of traditional social and natural sciences, or any singular discipline, and as a result SES as a research field lacks its own coherent methodological identity, instead drawing strongly on methodological pluralism (Tengö et al. 2014, Folke et al. 2016). Fluidity of identity is also evident in the multiple terms used to describe SES (e.g., coupled human-environmental systems, manenvironmental systems), varied definitions for what SES are (Herrero-Jáuregui et al. 2018, Colding and Barthel 2019), and the different ways that SES are spoken about in academic literature, ranging from a boundary object to bridge disciplines (Hertz and Schlüter 2015) to describing real epistemic systems that can be understood using empirical methods (Becker 2012).

Although a variety of conceptual and methodological ambiguities plague this emerging research area, there is sufficient coherence to enable analysis of key dimensions of this research field. All SES research has in common a nomenclature that designates the object of study as having integrated social and ecological components, as is also reflected in the names of prominent journals in the field. Indeed, several recent reviews have attempted such analyses of the SES field (Binder et al. 2013, Turner et al. 2016, Herrero-Jáuregui et al. 2018, Partelow 2018, Colding and Barthel 2019). From these reviews, it is clear that SES research, which is often approached alongside concepts such as ecosystem services, sustainability science, and transdisciplinary research (Brandt et al. 2013, Turner II et al. 2016, Haider et al. 2018, Herrero-Jáuregui et al. 2018, Partelow 2018), has grown over the past 20 years (Droste et al. 2018, Herrero-Jáuregui et al. 2018, Colding and Barthel 2019). Having its origins in placebased, local resource management studies (Colding and Barthel 2019), the field is still largely characterized by place-based studies, especially at the local scale (Norberg and Cumming 2008, Becker 2012, Angelstam et al. 2013, Hertz and Schlüter 2015, Folke et

Erratum: In the original publication Figure 1 was incorrect. The correct Figure 1 was put into place on 20 January 2020.

${ }^{1}$ Department of Environmental Science, Rhodes University, South Africa, ${ }^{` C}$ Centre for Complex Systems in Transition, Stellenbosch University,

South Africa, ${ }^{3}$ Stockholm Resilience Centre, Stockholm University, Sweden 
al. 2016). Meta-approaches/comparative analyses and framework development are, however, also often conducted (Partelow 2018). Indeed, several large databases now exist to collect case studies for meta-analyses, e.g. SESMAD, SESGO, IFRI (Partelow 2018). SES research derive from a broad range of disciplines, including the environmental, social, agricultural, biological, Earth and planetary, and computer sciences, as well as medicine and the humanities (Colding and Barthel 2019). Although the focus of SES research has shifted slightly over time (Droste et al. 2018, Herrero-Jáuregui et al. 2018), studies on adaptive management, governance, restoration, and poverty alleviation in sectors such as fisheries, forestry, and watersheds have been popular throughout (Droste et al. 2018, Herrero-Jáuregui et al. 2018, Partelow 2018).

A picture of the SES field has thus started to emerge, but the SES oncept is nevertheless still in transition (Herrero-Jáuregui et al. 2018), and there are gaps in our understanding of how the field functions and develops (Colding and Barthel 2019). Aside from lacking a broadly agreed-upon definition for SES (HerreroJáuregui et al. 2018, Colding and Barthel 2019), much of this gap relates to the methodological pluralism that characterizes the field (Partelow 2018). Methodological pluralism creates challenges for synthesis and data comparison, in part because it is more difficult to know what methods can and should be used in research (Partelow 2018). Lack of methodological transparency hampers attempts to generalize across case studies and frameworks (Magliocca et al. 2018, Colding and Barthel 2019), and can prove particularly challenging for postgraduate students and other early-career researchers (Haider et al. 2018). Understanding and interrogating methods used in the SES field is also important because of the nature of the systems being investigated. There is increasing agreement that SES can be conceptualized as complex adaptive systems (CAS) (Liu et al. 2007b, Levin et al. 2013, Rogers et al. 2013, Folke et al. 2016, Preiser et al. 2018, Herrero-Jáuregui et al. 2018), which place demands on the approaches and methods that SES researchers employ (Preiser et al. 2018), and necessitates an understanding and interrogation of the methods used in the field.

We thus expand on recent reviews of the development of the SES field, focusing specifically on the methods used in empirical, place-based SES research. We define methods as codified ways of producing knowledge of a focus of interest, a specific information-generating practice (Pahl-Wostl et al. 2013, Stirling 2015). By having a clearer idea of the range of methods that SES researchers are using when engaging in real-world problemsolving or solution-based research, we can improve our characterization of SES research as a field of inquiry, and also help guide researchers new to the field in identifying and selecting appropriate research methods.

We used a systematic review approach to conduct a broad analysis of the different terms being used to study coupled social and ecological systems and characterize these studies according to their type, distinguishing place-based studies from studies that outline "frameworks" and "reviews." Focusing on a subset of place-based research, we then identified the journals, institutions, and countries in which SES have been studied, and how these have changed over time. Having broadly contextualized SES research, we identified a large set of methods used in place-based research, and explored the topics or problems they have most commonly sought to investigate. We summarized the methods into categories, providing a typology that can serve as a guide to the range of methods used in SES research.

Our positioning in this paper centers around the conceptualizations of SES as complex adaptive systems (CAS; Liu et al. 2007b, Levin et al. 2013, Rogers et al. 2013, Folke et al. 2016, Preiser et al. 2018). In this realm, Preiser et al. (2018) have recently made some progress in moving toward a cohesive, theoretically derived definition (Schlüter et al. 2012, Cumming 2014, Bots et al. 2015) of SES research. They offer a typology of six underlying organizing principles of CAS that characterize the various features and properties of such systems. This typology (Table 1) can be used to recognize and assess the demands that CAS make on the methods that SES researchers employ. A final goal of this paper was thus to relate the list of method categories to these underlying principles of CAS through an exploratory assessment of how well different method categories account for core features of CAS.

\section{METHODS}

Systematic reviews are synthesis-based approaches that have in common the aim to build new knowledge from a rigorous analysis of existing research findings (Thorne et al. 2004). Regardless of their aim, systematic reviews follow a strict protocol to maximize transparency and repeatability while minimizing bias (Petticrew and Roberts 2006, Pullin and Stewart 2006, Pullin and Knight 2009, Gough et al. 2012). The systematic review process can be summarized as: formulating a question, generating a protocol, systematic selection, critical appraisal of results, data extraction, data synthesis, and reporting and dissemination (Gough et al. 2012).

\section{Defining a search strategy and predocument selection}

After situating our study in the conceptual framework outlined in the introduction and defining our study questions, we conducted a first exploratory search in Google Scholar and Scopus databases. We used the search terms "social-ecological," "coupled human*," "SES," "CHANS," "coupled humanenvironment*," and "social relations to nature." We found that the acronyms "CHANS" and "SES" produced a lot of noise in our results, and subsequently dropped these from our search. During this exploratory phase, we discovered several additional terms that identified studies dealing with human-nature interactions, and included them in subsequent searches. The final terms used in our systematic review were: "social-ecological," "socio-ecological," "human environment," "human-environment*," "affective ecology*," "social-environmental," "socio-environmental," "human-nature relation*," "coupled human*," "human-earth relation*," "environment relation*," "human-environment*," "man-environment relation*," "eco-social," and "nature-society relation" (Appendix 1).

\section{Document selection}

Document selection was based on a key word search in Scopus, limited to the title, abstract, and key words. We chose Scopus because of its extensive and interdisciplinary coverage and high recognition as a standardized database for conducting metaanalyses (Wagner et al. 2011). Our first search, using the final key words above to search all journals in the Scopus database over all 
Table 1. Key complex adaptive systems features and attributes with related practical implications for understanding and governing complex adaptive systems (CAS), based on Preiser et al. (2018).

\begin{tabular}{ll}
\hline \hline $\begin{array}{l}\text { Underlying } \\
\text { features of CAS }\end{array}$ & Key features and attributes \\
\hline $\begin{array}{l}\text { Constituted } \\
\text { Relationally }\end{array}$ & $\begin{array}{l}\text { Process-dependent interactions } \\
\text { on multiple scales result in } \\
\text { networks of interactive relations. }\end{array}$ \\
& $\begin{array}{l}\text { CAS are defined more by the } \\
\text { interactions among their } \\
\text { constituent components than by } \\
\text { the components themselves. }\end{array}$ \\
& $\begin{array}{l}\text { All systems exhibit hierarchy in } \\
\text { that every system is part of a }\end{array}$ \\
& $\begin{array}{l}\text { wider system and is made up of } \\
\text { subsystems. }\end{array}$ \\
& $\begin{array}{l}\text { How we describe (or identify) } \\
\text { systems is a function of our } \\
\text { individual points of view. }\end{array}$ \\
& $\begin{array}{l}\text { Systemic interactions generate } \\
\text { effects that have impacts across } \\
\text { scales and domains. }\end{array}$ \\
& The identity and functions of \\
CAS are defined by the context \\
in which they exist.
\end{tabular}

Permeable boundaries, embeddedness, nestedness, exchange of matter, information, energy, and teleconnections.

CAS are continuously shaped by environment. dynamic interactions with their

Practical implications for engaging with CAS that characterize CAS features

Net-like structures, hierarchies, The nature and structure of relationships between diverse components, built-in redundancy, heterogeneity. components in a system have to be considered explicitly;

Collaborative processes should be fostered to build trust and social networks;

Diversity is key and allows for different kinds of interactions to take place.

Projects are not closed and contained entities, therefore any intervention will influence and shape systems and realities that are situated outside of the scope of the project's aims and objectives;

Changes at local scales from individual decisions result in cumulative changes that have impacts globally and similarly, global events have impacts on local ecosystems and communities.

Systems must be understood in the context of their environment;

Changing a system affects both its subsystems and the environment in which it is embedded;

Transformative spaces should be created for activating systemic change processes.

CAS have self-organizing
capacities and can adjust their
behavior as a response to changes
in their environments.

Self-generating, self-organization, Guard against rigid planning and strategy design and decentralized control, has memory, implement adaptive comanagement practices that foster evolutionary, concurrent iterative learning and participatory collaborative processes of persistence and change (resilience), engagement; anticipa- tory capacities.

Foster iterative learning and participatory collaborative processes of engagement;

Assess resilience and anticipate possible future organizational patterns and pathways.

Far-from-equilibrium, nonlinear Map systemic feedbacks across different spatial and temporal interactions, attractors, thresholds; scales to identify systemic thresholds, traps, and indicators tipping points, regime-shifts, feedback loops (enabling and bring about the behavioral patterns of CAS.

As a result of nonlinear feedback loops that can dampen or amplify perturbations, small changes can have significant, cascading effects resulting in multiple modes of system-wide reorganization or regime shifts.

Complex Through the interaction of the Causality individual components, novel qualities and phenomena emerg Hence, the whole is more than the sum of its parts, meaning that systems cannot be understood, nor their behavior predicted based solely on information relating to the individual parts.
Assess which mechanisms build or inhibit systemic agency and resilience.
Emergence and novelty come Cause-and-effect cannot be traced in linear causal trajectories, about through complex underlying thus manage for emergence and expect unintended mechanisms. consequences;

CAS are inherently unpredictable and deeply uncertain;

Foster responses that are flexible to redefine outcomes and responses as necessary. years, yielded over 20,000 documents. This included results from the mental health, engineering, and information technology literature, which were not relevant to our study. We thus removed results with the key words "adolescent," "male" and "female," "middle aged," "aged," and "child" because these were associated with social-ecological critical theory in psychology, which is different from the SES focus of this article. We also restricted the search to the subject areas of environmental science, social 
science, agricultural and biological science, Earth and planetary science, economics, econometrics and finance, energy, "multidisciplinary," and decision sciences. We excluded environmental education because the overlaps with the health and psychological literature produced a lot of nonrelevant studies. Further, we restricted our search to journals, books, and book series, and to publications in English, and items published or in press. Our final search, conducted on 22 July 2015, yielded a result of 5222 documents. In addition to the abstracts and (index and author) key words, we downloaded the year published, journals published in, number of citations, and the institutions and geographical locations of authors.

\section{First screening and coding}

The next step was to screen abstracts for inclusion or exclusion in the study. We characterized papers as follows:

- Review: a review of papers about SES, theoretical concepts, and/or frameworks;

- Framework: papers that explicitly proposed a framework for understanding SES;

- Framework and place-based: papers that proposed a framework, and also used this framework to analyze a placebased system;

- Theory: articles that did not propose a framework, but focused on understanding an aspect of thinking about SES, or developing SES theory, without focusing on a particular place-based SES;

- Place-based article: empirical studies that focused on placedbased SES;

- Irrelevant: studies that very clearly did not make reference to SES as integrated social and ecological systems and were not relevant to the focus of this study, e.g., studies focusing on the psychological social-ecological theories that were not filtered out in the initial search. These articles (124) were not further considered in our review. Removing these articles brought our total database to 5098 records.

\section{Second screening and document analysis}

In the second screening of abstracts, we focused only on the documents that were classified as place-based articles (4479 articles). Of these $4479,37.4 \%$ contained the term "socialecological" in their title, abstracts, and key words, while $61.4 \%$ contained the term in their full texts. To keep the analysis manageable, we randomly selected 2000 of these place-based articles, and read the abstract, title, and key words. For each article, we recorded the scale of the SES studied (local, regional, national, multinational, and global), as well as research methods used (as could be derived from the abstract and key words). We did not classify articles where we could not infer methods used from the abstract ( 293 of the 2000 surveyed documents). This left 1707 read and classified articles. Scopus records the research affiliations and countries of researchers affiliated with papers; we thus had these data for the full dataset, i.e., 4479 articles. However, we also recorded, in the subset of data $(n=1707)$, the names of countries mentioned in the abstract and key words, i.e., the location where the research took place.

\section{Data analysis}

Growth and types of SES research

To track the development of the SES research field, we analyzed the growth of all SES publications $(n=5098)$ as a proportion of the total number of publications in Scopus within the same disciplines. We investigated the significance of the relationship between year and relative publications with a Spearman-rank test, and used both change point analysis (R package "changepoint"), and Bayesian change point analysis, to detect significant inflection points. We used a chi-squared test to statistically analyze the different types of SES papers (namely "theory," "framework," "place-based research," "review") across all years, against a null hypothesis of equal proportions.

\section{Hotspots of SES research}

From the full place-based data set $(n=4479)$, we used the names of countries and institutions associated with each research paper (as denoted by Scopus) to calculate the number of SES publications produced by each country and research institution over time. We weighted these totals by a notional research capacity for each country (number of universities per country as reported in the database of the International Association of Universities (IAU; http://www.whed.net/home.php). We compared the average research output/capita per year using ANOVA tests.

To identify hotspots of SES research sites, we calculated the number of place-based studies conducted in each country $(\mathrm{n}=$ 1707). We created a graduated heat map in ArcGIS 10.5 (ESRI 2017) using raw frequencies, as well as normalized frequencies, accounting for surface area. Countries were assigned to regions. After normalization of country frequencies, data were normally distributed, and we performed a one-way ANOVA to test for statistical significance between regions.

\section{Popularity of journals over time}

To assess the development of journals publishing SES research over time, we focused on the five most popular journals over all years. Here we used the full dataset $(n=5098)$. We recorded the proportion of total publications in each time period (1990-1990, 2000-2008, 2009-2012, 2013-2015). Time periods were informed by the results of the change point analysis. We performed a Kruskal-Wallis test to analyze differences in average annual number of SES publications between journals.

\section{Thematic topics in SES research}

We used word cloud and frequency analysis of author key words to extract major topics of SES research. We removed all spaces between words of key word terms (e.g., "ecosystem services" became "ecosystemservices"), so that we could run word cloud analysis on terms, rather than single words, using the wordCloud package in $\mathrm{R}$ (v3.01). We extracted the most frequent terms (see Appendix 2) from which we constructed a list of thematic topics for place-based SES research. We then searched the abstracts and author key words of all 4479 place-based studies to obtain the frequency with which these terms were used in the abstracts and key words of studies in our dataset. Finally, we constructed a twoby-two matrix of methods, highlighting main associations.

\section{Method extraction and categorization}

We manually screened key methods from 2000 abstracts of placebased SES studies, 1707 of which mentioned a research method. 
Abstracts varied in the number and detail of methods provided, for example, some would note that they had employed "modeling," while others detailed the type of models they used. This was particularly true for statistical methods, and data collection. In the first instance, we listed methods as they were listed in the abstract. We cleaned the resulting method list (632 individual methods, after removing of duplicates) by merging very similar methods. We also removed "methods" that we considered broader approaches, e.g., resilience assessment, adaptive management, transdisciplinary. This process produced a list of 311 methods (see Appendix 3).

We clustered these 311 methods into 27 categories, or method typologies, verifying and debating them in a workshop setting, held at the Stockholm Resilience Centre in October 2016. Our motivation for categorizing methods was twofold: (1) abstracts were not consistently detailed in the kind of methods that they highlighted; (2) it was difficult to conduct a meaningful analysis of more than 300 methods in a way that we could service our objective of providing an overview of the field. We assigned each method to a single category, although many methods could fit under several categories. Categories were based on the way that these methods were perceived to be used in SES research by experts at the workshop, and ones that were considered to have a similar function, or that had similar sets of assumptions. Some categories contained only one or two methods, e.g., agent-based modeling, because workshop participants felt that they were either very broadly used in SES research, or fulfilled a unique function. Conversely, other categories, e.g. statistical methods, contained a diversity of methods, but were not seen to play a unique role in SES research, and resources for their use are readily available. The final set of categories are intended to provide an entry point for discussion around methods that are being used in SES research, and not as a definitive list of methods that can or should be used.

To obtain the frequency of method categories in our database, we searched the full set of 4479 place-based studies for the 311 methods we had extracted from the subset of 2000 articles, and classified which categories each record belonged to. We were able to categorize 2742 of our place-based articles in this way. Thus, the remaining 1737 articles (38\%) either did not mention the methods we detected in our search, or did not mention any methods in their abstracts. Readers should thus keep in mind that the list of methods identified in this study was not comprehensive.

\section{Features and dynamics of complex adaptive systems}

We used Preiser et al.'s (2018) typology of six organizing principles of CAS (Table 1) to qualitatively assess each method category in terms of its ability to account for key organizing principles of CAS. By "account" we mean the extent to which a method's assumptions and application allow them to investigate systems that are constituted relationally, context-dependent, radically open, adaptive, dynamic, and have complex causality. We chose this typology on account of Preiser et al.'s (2018) clear conceptualization of SES as CAS. We distinguished between method categories that "did not account for this feature of complexity" (0); "can account for this feature of complexity, depending on how it is employed" (1, sometimes); "can account for this feature of complexity, and is usually employed in a way that does" (2, most times); and "explicitly accounts for this element of complexity in the way it is constituted" (3, always). In our analysis, we considered the ways in which the different types of methods are, to our knowledge, normally used. Each of the authors independently scored the method clusters against each principle, and subsequently debated the scores that we disagreed on. Based on our discussions, we simplified our scores into two categories: "does not usually account for this complexity feature" $(0)$, and "usually accounts for this complexity feature" (x).

\section{RESULTS}

\section{Terms used}

Of the chosen search terms, "nature society relations" (71.8\%), "social-ecological" (31.78\%), "man-environment* relations" (29.67\%), "socio-ecological" (17.15\%), "social-environmental" $(12.1 \%)$, and "coupled human*" $(3.2 \%)$ were the most commonly used in the full final result set $(n=5098)$. Many publications contain more than one of these key words. The term "manenvironment* relations" and "human environment" appeared to be more popular in earlier years, whilst the term "socialecological," "socio-ecological" and "nature-society relations" have become more dominant in recent years (Fig. 1).

\section{Growth of the SES research space}

Our results show that there is a significant increase in the number of publications in the SES space, relative to the growth in all publications over time (Spearman's rank correlation, $p<0.01$, $r h o=0.0823$ ). Significant change points were detected between 1989 and 1990, between 1999 and 2000, and 2009 and 2010. A single change point analysis revealed the change between 1999 and 2000 to be the most significant change point $(\mathrm{p}<0.05)$. Similarly, the Bayesian change point analysis revealed most probable change points between 1989 and 1990 (prob $=0.99, \chi^{2}$ $=0.0003), 1999$ and 2000 (prob $\left.=0.952, \chi^{2}=0.002\right)$, but put a third change point between 2012 and 2013 (prob $0.940, \chi^{2}=0.002$ ). A fourth change point, between 2008 and 2009, had a posterior probability of 0.604 (Fig. 2). A posterior probability is a term in Bayesian statistics that refers to the conditional probability assigned to a proposition after relevant evidence has been considered (Lee 2012).

\section{Journals over time}

We identified 1234 different sources that published papers on SES. The top 20 journals each published between $0.63 \%$ and $7.73 \%$ of all publications, accounting for $28.05 \%$ of publications in total (Fig. 3a). There were significant differences in the median number of publications between the five most prominent journals $\left(\chi^{2}=\right.$ $32.1302, \mathrm{DF}=4, \mathrm{p}<0.0001)$, with Ecology and Society having significantly more publications (compared to Ambio, $\mathrm{p}<0.0001$, Ecological Economics, $\mathrm{p}=0.019$, Global Environmental Change, $\mathrm{p}=001$, Journal of Environmental Management, $\mathrm{p}<0.0001$ ). There were no significant differences between other journals (Fig. 3b). Ambio and Global Environmental Change published proportionally more papers in the SES field prior to 2000, while Ecology and Society has become increasingly dominant as the main journal publishing SES research since 2000 (Fig. 3c).

\section{Types and scale of SES research}

There was a significant difference in the type of SES papers published $\left(\chi^{2}=6589.523, \mathrm{df}=3, \mathrm{p}<0.01\right)$. Of the 5098 papers in our final database, $71(1.39 \%)$ explicitly proposed frameworks without applying these frameworks to real-world case studies, or 
Fig. 1. Trends in the use of the seven most common search terms in this study, expressed as a proportion of the total number of new social-ecological systems research published in a given time period (as determined by change point analysis, Fig. 2).

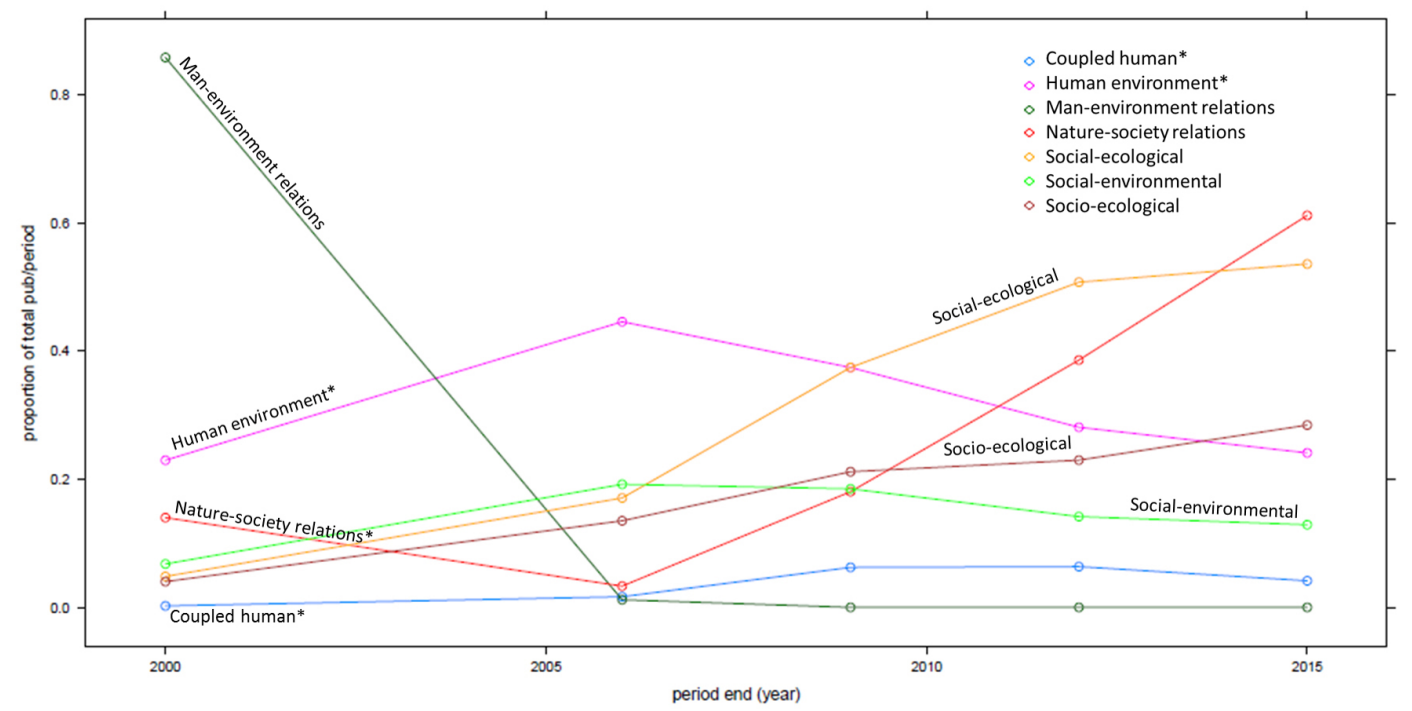

Fig. 2. Social-ecological systems publications as a proportion of all publications in our assessed disciplines in Scopus, plotted over time (y-axis, right). The bottom segment shows posterior probability of change points occurring between each year. Most probable change points (prob $<0.6$ ) are marked with years on the dividing line.

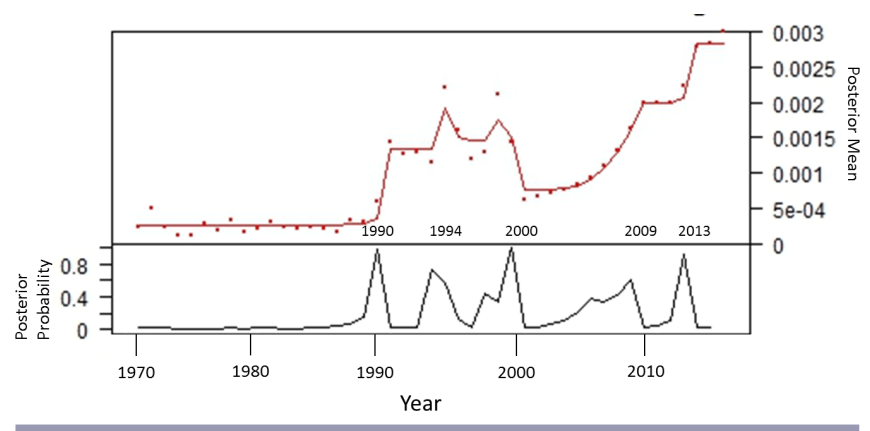

comprised other theoretical discussions. A further 703 papers $(13.79 \%)$ proposed frameworks and applied those frameworks to place-based research, $3792(74.38 \%)$ of papers focused on placebased research, and $532(10.44 \%)$ were reviews. Our results show that SES research has been more focused on the local scale $(45 \%$ of all publications) compared to the regional (28\%), national $(11 \%)$, multinational $(8 \%)$, and global $(6 \%)$ scales $\left(\chi^{2}=2802.7\right.$, df $=4, \mathrm{p}<0.0001)$.

Hotspots of SES researchers and research

As measured by raw number of publications, European, North American, and Australasian institutions have contributed most significantly to SES research (Fig. 4a, b), with the United States,
Canada, Sweden, Australia, the Netherlands, Germany, the United Kingdom, and South Africa emerging as countries with particularly high number of institutions that study SES. When normalizing institutional paper count by the number of higher education institutions in the country, Kenya, Denmark, and New Zealand were also included as hotspot countries. The lead authors of institutions publishing SES research was most frequently associated with Stockholm University (199 studies), Arizona State University (179 studies), Wageningen University (97 studies), James Cook University (79 Studies), and the University of Queensland (71 studies; Table 2).

Whereas institutions conducting SES research were clustered in the Global North, the SES being investigated were distributed more broadly across the globe (Fig. 4c, d). Studied SES were most frequently reported to be located in the United States (422), China (226), Australia (169), India (167), Canada (142), Brazil (134), and Mexico (100). A one-way ANOVA revealed significant differences between regions $(\mathrm{F}=5.068, \mathrm{P}<0.001$, df $=14$; Fig. $5)$, but a posthoc Tukey test revealed that significant differences were mostly between island regions and mainland areas, and that most mainland areas were not significantly different from each other, on average. Even when accounting for size, the Caribbean Islands were understudied compared to most regions. It had a significantly mean lower normalized frequency than Asia (diff = $0.146, p<0.001$ ), the Middle East (diff $=0.113, p<0.039$ ), North and Central America (diff $=0.186, \mathrm{p}<0.001$ ), South America (diff $=0.125, p=0.016)$, Southern Africa $($ diff $=0.136, p=0.029)$, West Africa (diff $=0.101, p=0.045)$, and West and Central Europe (diff $=0.124, p<0.001$ ). Another region that is poorly studied is Oceania, which was significantly underrepresented compared to both Asia (diff $=0.101, \mathrm{p}<0.001)$ and North and Central 
Fig. 3. Journals that most frequently publish research on social-ecological systems (SES). Fig. 3(a) shows the proportion of SES publications published by the 20 top journals across all years. Fig. 3(b) shows the proportion of SES publications published in the top five journals across all years, broken down by time period. Fig. 3(c) shows mean number of SES publications/year for each of the top five journals.

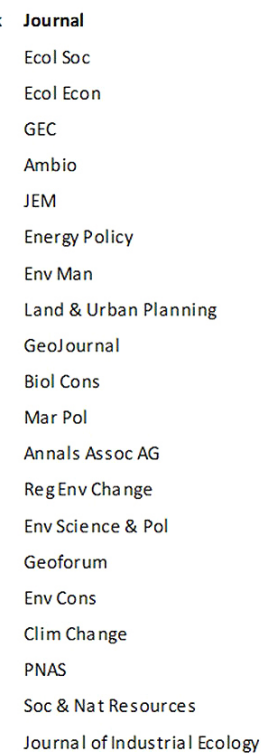

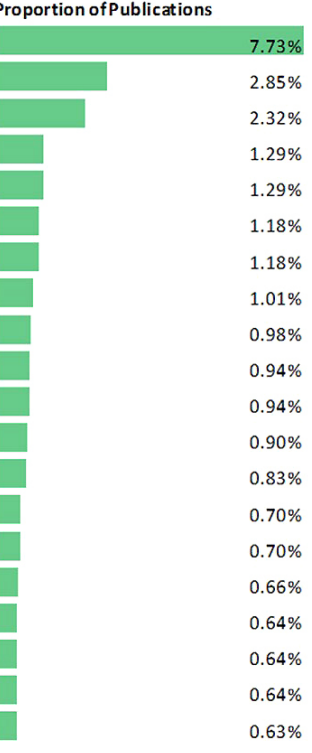

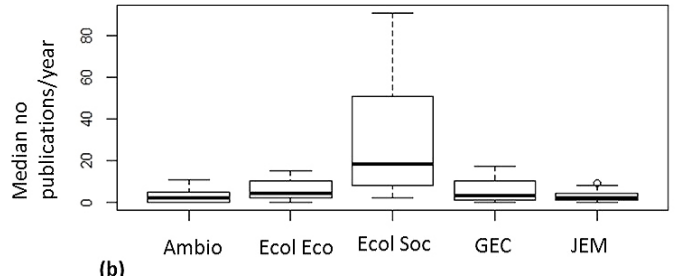

(b)

Journal

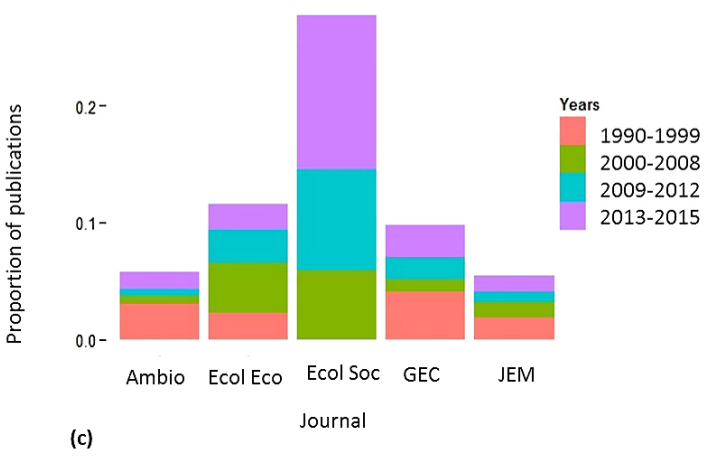

Table 2. Institutions with the highest number of social-ecological systems studies, based on author affiliations in Scopus.

\begin{tabular}{llcc}
\hline \hline Institution & Country & $\begin{array}{c}\text { No. of } \\
\text { Studies }\end{array}$ & $\begin{array}{c}\text { Prop. of } \\
\text { Publications }\end{array}$ \\
\hline Stockholm University & Sweden & 199 & 0.043 \\
Arizona State University & USA & 139 & 0.030 \\
Wageningen University & Netherlands & 97 & 0.021 \\
James Cook University & Australia & 79 & 0.017 \\
University of Queensland & Australia & 71 & 0.015 \\
University of Alaska & USA & 68 & 0.015 \\
Fairbanks & & & \\
University of East Anglia & UK & 68 & 0.015 \\
The University of British & Canada & 63 & 0.014 \\
Columbia & & 60 & 0.013 \\
University of Wisconsin & USA & & \\
Madison & & 59 & 0.013 \\
Indiana University & USA & 58 & 0.013 \\
University of Oxford & UK & 53 & 0.012 \\
University of Manitoba & Canada & 51 & 0.011 \\
Australian National & Australia & & \\
University & & 50 & 0.011 \\
University of Victoria & Canada & 49 & 0.011 \\
University of California & USA & 49 & 0.011 \\
Berkeley & & 48 & 0.010 \\
University of Florida & USA & 48 & 0.010 \\
Stanford University & USA & 46 & 0.010 \\
University of Waterloo & Canada & & \\
Swedish Royal Academy of & Sweden & & \\
Science & & & \\
University of California & USA & & \\
Santa Barbara & & & \\
\hline
\end{tabular}

America (diff $=0.142, p=0.006)$. Predominantly mainland regions that were significantly underrepresented compared to other regions were Antarctica and South Sea Islands (compared to North and Central America, diff $=0.191, p=0.03$ ), and Central Africa (compared to North and Central America, diff $=0.159, \mathrm{p}$ $=0.031)$.

\section{Topics of SES investigation}

A word cloud analysis (Fig. 6a) extracted 518 terms that were used more than five times in 2198 of 4479 place-based studies with author-provided key words. We subsequently searched all abstracts and key words of the full dataset of articles (4479 studies) for the identified key words. Searching the full dataset, and combining some key terms (see Appendix 2), changed the prominence of key terms slightly. In the final analysis, the top 20 terms differed significantly $\left(\chi^{2}=5326.377\right.$, df $\left.=25, p<0.0001\right)$ in the frequency with which they were used in the literature. The terms that were most frequently encountered in author key words were (variations of) "policy" (30.8\% of publications), "trade" (23.8\%), "conservation" (22.3\%), "adaptation" $(22.3 \%)$, "land use change" (21.9\%), "water" (20.2\%), "forest loss" (19.9\%), "sustainability" (18.8\%) and "urban" (18.8\%) and "governance and institutions" (17.5\%; Fig 6b, Appendix 2).

\section{Methods used}

We grouped 311 methods (reduced from an initial list of 632 , Appendix 3) into 27 categories (Fig. 7). Frequency of use (in 2742 studies) differed significantly between categories $\left(\chi^{2}=4231.068\right.$, $\mathrm{DF}=26, \mathrm{p}$-value $<0.001)$. Spatial mapping and analysis $(27.5 \%)$, historical profiling and reconstruction (15.7\%), interviews $(15.5 \%)$, futures analysis $(13.3 \%)$, participatory data collection $(11.9 \%)$, and impact analysis $(11.2 \%)$ were the most frequently 
Fig. 4. Hotspots of global social-ecological systems (SES) research, and institutions studying SES. Figure 4(a) shows a heat map of raw total number of studies from institutions studying SES, while (b) shows a heat map based on normalized counts. Figure 4(c, raw) and (d, normalized) show the number of SES studies conducted in countries around the world.

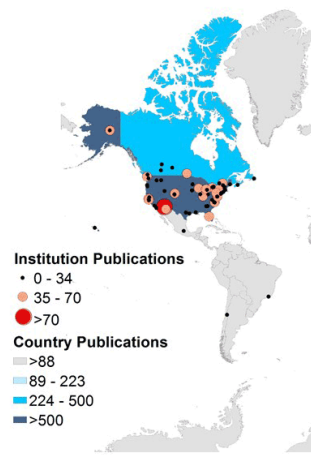

(a) Institutional Hotspots Raw

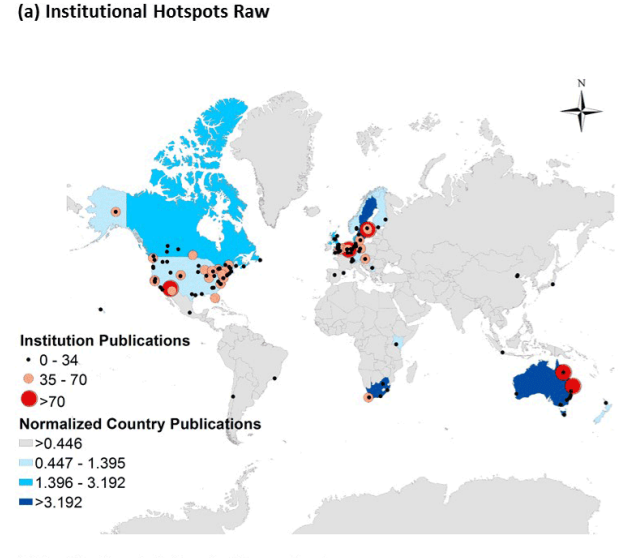

(b) Institutional Hotspots Normalized

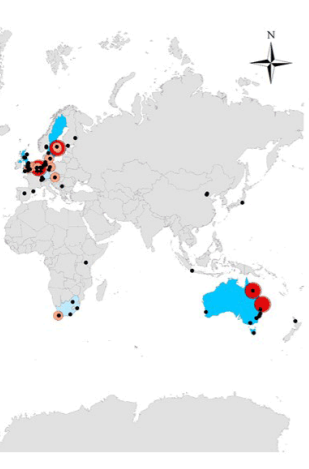

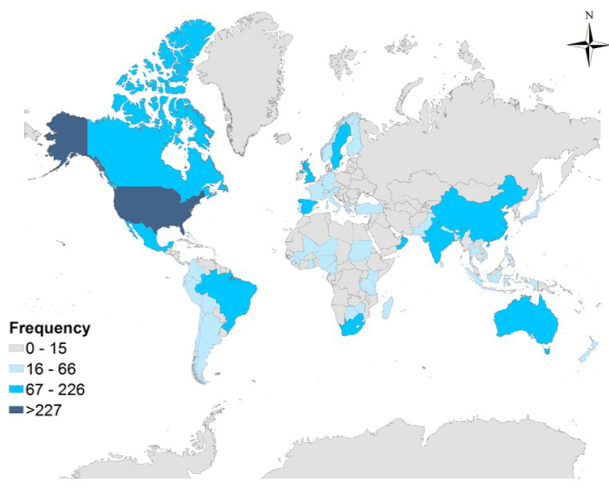

(c) Studied SES Hotspots Raw

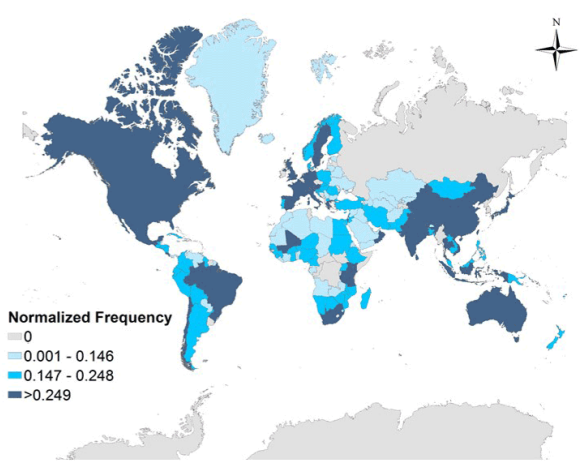

(d) Studied SES Hotspots Normalized
Fig. 5. Mean number of studies conducted in different global regions, per country, normalized by land area. Asterisks (*) denote significant difference.

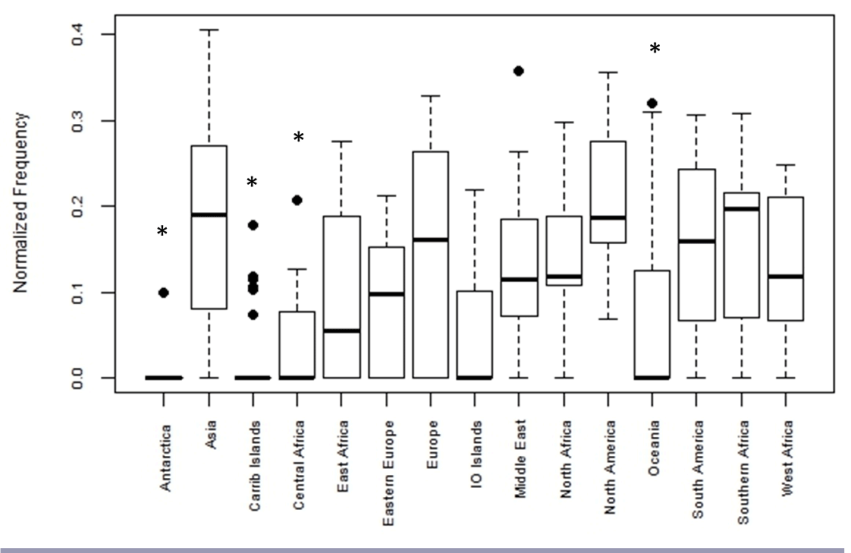

used method categories (Fig. 7). "Historical profile and reconstruction," "futures analysis," "spatial mapping and analysis," "livelihood and vulnerability analysis," "impact analysis," "network analysis," "participatory modeling and planning," and "decision analysis" were the categories that were most frequently associated with the 20 most identified focus topics (Table 3).

\section{Methods addressing complexity features}

Table 4 shows how well each method category scores in terms of its ability to account for each characteristic of complexity, zero ("0") being "usually not well" and " $x$ " being "usually well," along with a justification for each scoring decision. We judged "futures analysis," "comparative case study analysis," "behavioral analysis," "decision analysis," "games," "systems scoping," "participatory modeling and planning," "state-and-transition analysis," "historical profiling and reconstruction," "discourse analysis," and "facilitated dialogues" to be method categories that usually address all six features of CAS (mean score =1). Method categories "optimization analysis," "impact analysis," "quantitative pattern recognition," and "statistical analysis" were reasoned to address features of complexity least well. The features of complexity that were best addressed were "constituted relationally," followed by "contextual" and "dynamic," "adaptive," "complex causality" and "radically open." 
Table 3. Method categories most often used to investigate topics of concern, ordered from most to least commonly identified focus topics.

\begin{tabular}{|c|c|}
\hline Topic & Top three most used method categories \\
\hline Policy & Futures analysis $(12.1 \%)$, spatial mapping and analysis $(11.7 \%)$, historical profiling and reconstruction $(10.1 \%)$ \\
\hline Trade & Decision analysis $(15 \%)$, impact analysis $(15 \%)$, futures analysis $(13.7 \%)$ \\
\hline Conservation & Historical profiling and reconstruction (14\%), spatial mapping and analysis $(11.7 \%)$, futures analysis $(9.4 \%)$ \\
\hline Adaptation & Historical profiling and reconstruction $(24.4 \%)$, livelihood and vulnerability analysis $(8.8 \%)$, futures analysis $(8.8 \%)$ \\
\hline Land use change & Spatial mapping and analysis $(20.7 \%)$, historical profiling and reconstruction $(15 \%)$, futures analysis $(10.6 \%)$ \\
\hline Water & Historical profiling and reconstruction (18\%), spatial mapping and analysis $(12.3 \%)$, futures analysis $(9.5 \%)$ \\
\hline Forest loss & Historical profiling and reconstruction (16\%), spatial mapping and analysis $(12.6 \%)$, futures analysis $(9.9 \%)$ \\
\hline Sustainability & Historical profiling and reconstruction $(12.5 \%$, futures analysis $(10.5 \%)$, impact analysis $(8.6 \%)$ \\
\hline Governance and institutions & Historical profiling and reconstruction $(18.6 \%)$, network analysis $(8.8 \%)$, spatial mapping and analysis $(7.2 \%)$ \\
\hline Risk and uncertainty & Impact analysis $(16.2 \%)$, historical profiling and reconstruction $(13.4 \%)$, futures analysis $(10.8 \%)$ \\
\hline Climate change & Historical profiling and reconstruction $(17.4 \%)$, futures analysis $(16 \%)$, livelihood and vulnerability analysis $(9.2 \%)$ \\
\hline Resilience & Historical profiling and reconstruction $(24.7 \%)$, livelihood and vulnerability analysis $(10.2 \%)$, futures analysis $(9 \%)$ \\
\hline Ecosystem services & Futures analysis $(14.1 \%)$, historical profiling and reconstruction $(11.5 \%)$, spatial mapping and analysis $(10.6 \%)$ \\
\hline Vulnerability & Livelihood and vulnerability analysis $(47.2 \%)$, historical profiling and reconstruction $(13.8 \%)$, futures analysis $(8.1 \%)$ \\
\hline Agriculture & Historical profiling and reconstruction $(15.9 \%)$, futures analysis $(14 \%)$, spatial mapping and analysis $(10.2 \%)$ \\
\hline Fisheries & Historical profiling and reconstruction $(15.4 \%)$, futures analysis $(10.7 \%)$, participatory modeling and planning $(7.6 \%)$ \\
\hline Biodiversity & Spatial mapping and analysis $(14.4 \%)$, historical profiling and reconstruction $(12.9 \%)$, futures analysis $(8.8 \%)$ \\
\hline Livelihoods & $\begin{array}{l}\text { Historical profiling and reconstruction }(23.5 \%) \text {, livelihood and vulnerability analysis }(11.7 \%) \text {, spatial mapping and } \\
\text { analysis }(10.1 \%)\end{array}$ \\
\hline Urban & Historical profiling and reconstruction $(15.3 \%)$, spatial mapping and analysis $(12.3 \%)$, futures analysis $(9.4 \%)$ \\
\hline Food security & Historical profiling and reconstruction $(15.6 \%)$, futures analysis $(13.7 \%)$, spatial mapping and analysis $(10 \%)$ \\
\hline Transformation & Historical profiling and reconstruction $(20.5 \%)$, futures analysis $(9.8 \%)$, spatial mapping and analysis $(9 \%)$ \\
\hline Drought and desertification & $\begin{array}{l}\text { Historical profiling and reconstruction (18\%), livelihood and vulnerability analysis }(14 \%) \text {, spatial mapping and } \\
\text { analysis }(11 \%)\end{array}$ \\
\hline Natural resource management & $\begin{array}{l}\text { Historical profiling and reconstruction }(15.3 \% \text {, participatory modeling and planning }(8.3 \%) \text {, agent-based modeling } \\
(8.3 \%) \text {, network analysis }(8.3 \%)\end{array}$ \\
\hline Poverty & Historical profiling and reconstruction $(15.3 \%)$, spatial mapping and analysis $(12.9 \%)$, futures analysis $(12.5 \%)$ \\
\hline Social and environmental justice & $\begin{array}{l}\text { Spatial mapping and analysis }(14.6 \%) \text {, historical profiling and reconstruction }(12.5 \%) \text {, quantitative pattern } \\
\text { recognition }(8.3 \%)\end{array}$ \\
\hline $\begin{array}{l}\text { Common pool resource } \\
\text { management }\end{array}$ & $\begin{array}{l}\text { Participatory modeling and planning }(18.75 \%) \text {, agent-based modeling }(18.75 \%) \text {, historical profiling and } \\
\text { reconstruction }(12.5 \%) \text {, network analysis }(12.5 \%)\end{array}$ \\
\hline
\end{tabular}

Fig. 6. (a) Word cloud showing the key issues, as generated from author key words that are the focus of social-ecological systems (SES) research, (b) shows the proportion of total publications that mention each topic in their author key words.

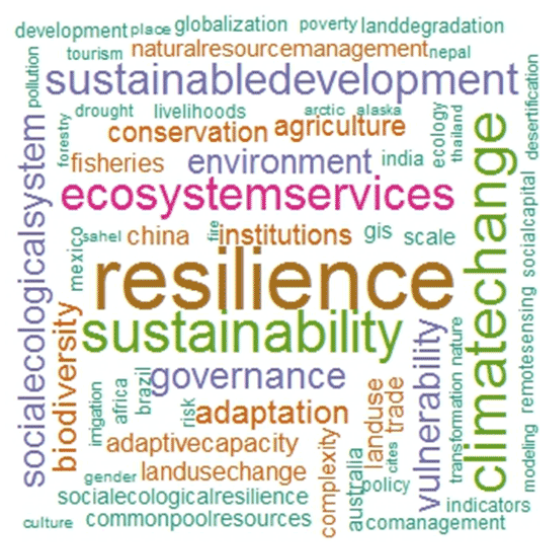

(a)

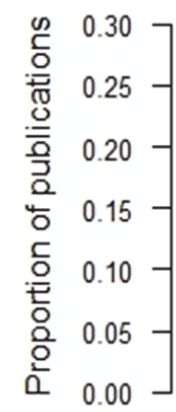

(b)

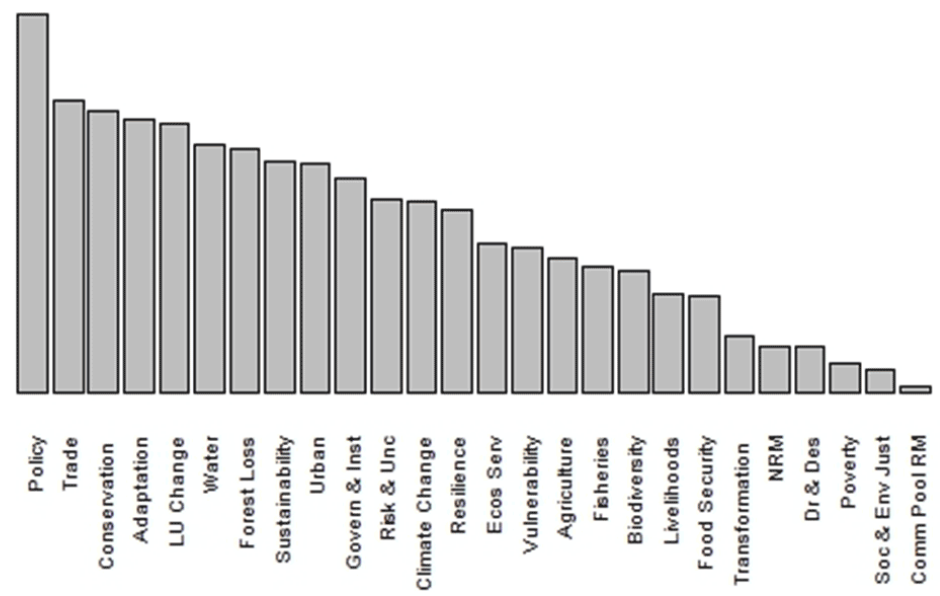

\section{DISCUSSION}

Our study provides insights on trends in the SES research field in terms of the terminology used, journals being published in, the type of research, where it is being done and by whom, topics being investigated, and the methods being used. Although a number of reviews (Brandt et al. 2013, Droste et al. 2018, Herrero-Jáuregui et al. 2018, Partelow 2018, Colding and Barthel 2019) exploring similar issues have recently been published, our analysis takes a particularly broad view, and specifically focuses on the methods used in SES field through a list of method "categories" or typologies, also assessing the extent to which they account for the underlying organizing principles of CAS. Here we discuss five broad conclusions from these results, and their implications for advancing SES research. 
Table 4. Authors' assessment of the ability of different methods to account for the six features of complex adaptive systems. An "x" denotes methods that account well for the relevant underlying principle of complex adaptive systems. Justification for author choices are provided in Appendix 4.

\begin{tabular}{|c|c|c|c|c|c|c|c|}
\hline $\begin{array}{l}\text { Ra- } \\
\text { nk }\end{array}$ & Method Category & $\begin{array}{l}\text { Constituted } \\
\text { Relationally }\end{array}$ & $\begin{array}{c}\text { Radically } \\
\text { Open }\end{array}$ & $\begin{array}{c}\text { Context } \\
\text { Dependent }\end{array}$ & Adaptive & Dynamic & $\begin{array}{l}\text { Complex } \\
\text { Causality }\end{array}$ \\
\hline 1 & Spatial mapping $\&$ analysis & $\mathrm{x}$ & $\mathrm{x}$ & & $\mathrm{x}$ & $\mathrm{x}$ & \\
\hline 2 & Historical profiling \& reconstruction & $\mathrm{x}$ & $\mathrm{x}$ & $\mathrm{x}$ & $\mathrm{x}$ & $\mathrm{x}$ & $\mathrm{x}$ \\
\hline 3 & Interviews & $\mathrm{x}$ & $\mathrm{x}$ & $\mathrm{x}$ & & & \\
\hline 4 & Futures analysis & $\mathrm{x}$ & $\mathrm{x}$ & $\mathrm{x}$ & $\mathrm{x}$ & $\mathrm{x}$ & $\mathrm{x}$ \\
\hline 5 & Participatory data collection & $\mathrm{x}$ & $\mathrm{x}$ & $\mathrm{x}$ & & & \\
\hline 6 & Impact analysis & $\mathrm{x}$ & & & & & \\
\hline 7 & Livelihood \& vulnerability analysis & $\mathrm{x}$ & & $\mathrm{x}$ & $\mathrm{x}$ & $\mathrm{x}$ & $\mathrm{x}$ \\
\hline 8 & Statistical analysis & $\mathrm{x}$ & $\mathrm{x}$ & & & & \\
\hline 9 & Decision analysis & $\mathrm{x}$ & $\mathrm{x}$ & $\mathrm{x}$ & $\mathrm{x}$ & $\mathrm{x}$ & $\mathrm{x}$ \\
\hline 10 & Network analysis & $\mathrm{x}$ & & $\mathrm{x}$ & $\mathrm{x}$ & $\mathrm{x}$ & $\mathrm{x}$ \\
\hline 11 & Agent-based modeling & $\mathrm{x}$ & & $\mathrm{x}$ & $\mathrm{x}$ & $\mathrm{x}$ & $\mathrm{x}$ \\
\hline 12 & Dynamical systems modeling & $\mathrm{x}$ & & & $\mathrm{x}$ & $\mathrm{x}$ & $\mathrm{x}$ \\
\hline 13 & Participatory modeling \& planning & $\mathrm{x}$ & $\mathrm{x}$ & $\mathrm{x}$ & $\mathrm{x}$ & $\mathrm{x}$ & $\mathrm{x}$ \\
\hline 14 & Quantitative pattern recognition & $\mathrm{x}$ & $\mathrm{x}$ & & & & \\
\hline 15 & Discourse analysis & $\mathrm{x}$ & $\mathrm{x}$ & $\mathrm{x}$ & $\mathrm{x}$ & $\mathrm{x}$ & $\mathrm{x}$ \\
\hline 16 & Behavioral analysis & $\mathrm{x}$ & $\mathrm{x}$ & $\mathrm{x}$ & $\mathrm{x}$ & $\mathrm{x}$ & $\mathrm{x}$ \\
\hline 17 & Comparative case study analysis & $\mathrm{x}$ & $\mathrm{x}$ & $\mathrm{x}$ & $\mathrm{x}$ & $\mathrm{x}$ & $\mathrm{x}$ \\
\hline 18 & Biophysical, ecosystem, and ecological modeling & $\mathrm{x}$ & & & $\mathrm{x}$ & $\mathrm{x}$ & \\
\hline 19 & Ecological field data collection & $\mathrm{x}$ & $\mathrm{x}$ & $\mathrm{x}$ & & & \\
\hline 20 & Facilitated dialogues & $\mathrm{x}$ & $\mathrm{x}$ & $\mathrm{x}$ & $\mathrm{x}$ & $\mathrm{x}$ & $\mathrm{x}$ \\
\hline 21 & Bayesian methods & $\mathrm{x}$ & $\mathrm{x}$ & & $\mathrm{x}$ & & $\mathrm{x}$ \\
\hline 22 & Expert modeling & $\mathrm{x}$ & $\mathrm{x}$ & $\mathrm{x}$ & & $\mathrm{x}$ & $\mathrm{x}$ \\
\hline 23 & Institutional analysis & $\mathrm{x}$ & $\mathrm{x}$ & $\mathrm{x}$ & & & \\
\hline 24 & Optimization analysis & & & & & & \\
\hline 25 & Games & $\mathrm{x}$ & $\mathrm{x}$ & $\mathrm{x}$ & $\mathrm{x}$ & $\mathrm{x}$ & $\mathrm{x}$ \\
\hline 26 & Systems scoping & $\mathrm{x}$ & $\mathrm{x}$ & $\mathrm{x}$ & $\mathrm{x}$ & $\mathrm{x}$ & $\mathrm{x}$ \\
\hline 27 & State-and-transition analysis & $\mathrm{x}$ & $\mathrm{x}$ & $\mathrm{x}$ & $\mathrm{x}$ & $\mathrm{x}$ & $\mathrm{x}$ \\
\hline
\end{tabular}

\section{SES research is growing rapidly, but is still unevenly distributed} Similar to other reviews on SES and related fields (Brandt et al. 2013, Herrero-Jáuregui et al. 2018, Colding and Barthel 2019), we note significant increases in SES research over the last three decades, relative to the growth of scientific publications overall (Fig. 2). SES research is clearly spanning the social and natural sciences in terms of the subject fields of the main journals in which this research is being published (Fig. 3). The interdisciplinary journal Ecology and Society has become a dominant outlet, especially in recent years (Fig. 3). Its dominance may be partly attributed to being one of the earliest open access, online-only journals in the SES field. More recently (and not reflected in our results because of the time span analyzed), a number of new journals have been established in the SES field, including People and Nature (British Ecological Society), Ecosystems and People (Taylor \& Francis), and One Earth (Cell Press). These provide further evidence of the maturing of the SES field, and potentially broadening the core set of journals publishing SES research. This maturation is perhaps also evident from the analysis of key SES research terms, which reveals a variety of common terms used to describe the interactive relationship between human societies and the natural environment, and appears to currently be consolidating around the terms "nature society relations," "socialecological," and "socio-ecological" (Fig. 1). Consolidation around key terms and concepts is central to the development of new research fields (Guo et al. 2011).

SES research is dominated by a few institutions, notably Stockholm University in Sweden, Arizona State University
(USA), Wageningen University (Netherlands) and James Cook University (Australia). The top 20 research institutions conducting SES are all based in the Global North (mirroring the results of Herrero-Jáuregui et al. 2018), but SES being studied are more globally distributed (Fig. 4). Nevertheless, there are still large parts of the Earth where relatively little SES is being undertaken (Fig. 5). These include island regions such as the Caribbean, Indian Ocean Islands, Oceania, and inaccessible regions such as Antarctica. However, several populous regions are also little studied, including Central Africa, East Africa, West Africa, Eastern Europe, the Middle East, and North Africa. Several of these regions are undergoing rapid population growth and environmental change, experiencing pressing sustainability issues, and increasingly influencing regional and global changes in nature society relations. Better understanding context-specific SES dynamics in these regions to inform local and regional sustainability-related policies and actions is therefore a priority. Encouragingly, however, some of the places with the most SES research include Southern Africa and Asia, regions that are often not that well represented in environmental and social research more generally (Rodríguez-Pose 2006, Trimble and van Aarde 2012).

\section{SES research is dominated by place-based research at local to regional scales}

Our results point to the frequent use and development of new frameworks in SES research. Of all 5098 published papers assessed, $15.18 \%$ were framework papers, and only $1.39 \%$ were purely theoretical. The bulk $(13.79 \%)$ proposed frameworks that 
Fig. 7. Categories of methods used in social-ecological systems research, as categorized by the authors and collaborators in an expert workshop. The "example" column denotes examples within each method category. The "percentage of categorized publications" column indicates the percentage of total classified place-based publications that employed a method within the particular method category.

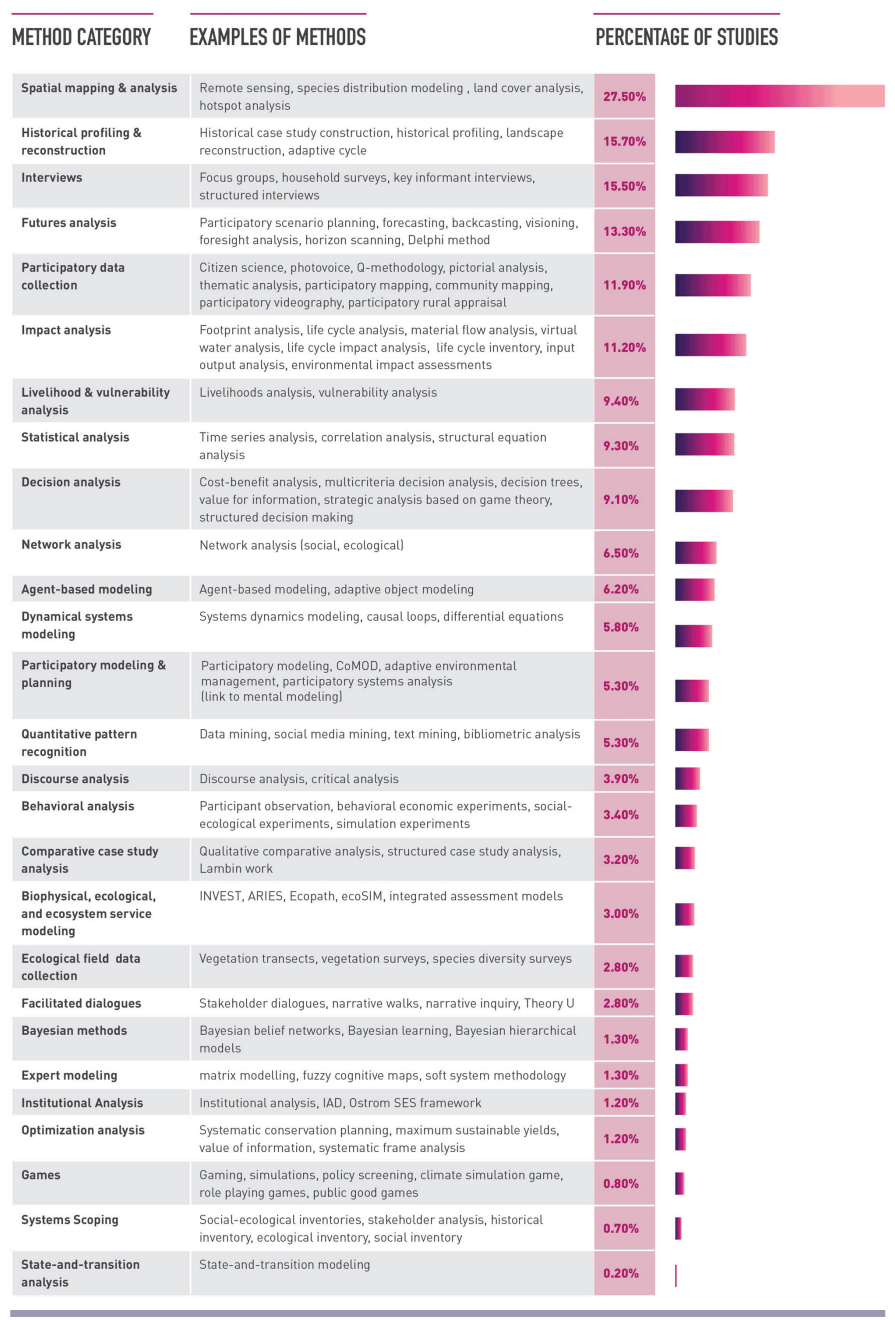

were applied to place-based systems, which may also suggest that the popularization of the term "social-ecological" systems was probably influenced by explicitly place-based frameworks (Colding and Barthel 2019). Although the high number of framework studies might be an indication that SES research is still in a developmental phase (counter to our earlier point), the strong place-based focus in the development of these frameworks suggests that customizing frameworks for new social-ecological contexts may be a characterizing feature of SES research. Colding and Barthel (2019) assert that many frameworks used in SES research are adaptations of three core frameworks; that of Ostrom (2007, 2009), Folke and Berkes (1998) and Berkes et al. (2003), and the robustness framework (Anderies 2004, 2007). All three of these have an explicit CAS-based underpinning.
Although a CAS lens is by no means the only way to conceptualize SES, it has become the most popular (Herrero-Jáuregui et al. 2018, Preiser et al. 2018). Our timeline analysis shows the most significant inflection point in the rise of SES research to lie between 1999 and 2000, which coincides with the establishment of the Resilience Alliance in 1999 (Folke 2006, Parker and Hackett 2012), and the initial publication of their affiliate journal Ecology and Society, which has published more SES research than any other journal (Fig. 3). The Resilience Alliance in particular, and Ecology and Society by association, relies heavily on CAS and resilience as key guiding frameworks (Herrero-Jáuregui et al. 2018, Preiser et al. 2018, Colding and Barthel 2019). Our results thus align with other studies that have highlighted the dominance of a CAS framing in influencing SES research (Herrero-Jáuregui et al. 2018, Preiser et al. 2018). Given the theoretical maturity of CAS (Preiser et al. 2018), we argue that a definition of SES as CAS, as attempted by Preiser et al. (2018), offers a pragmatic step toward a more universal definition of SES, often lamented as missing in the field (Herrero-Jáuregui et al. 2018, Partelow 2018, Colding and Barthel 2019). This is not to say, however, that CAS thinking is sufficient to support SES research, or that it excludes the use and integration of other frameworks.

\section{SES research is centered on pressing sustainability issues}

Key words identified in our study, similar to those found in related reviews (Brandt et al. 2013, Capstick et al. 2015, Droste et al. 2018, Herrero-Jáuregui et al. 2018), emphasize a focus of SES research on pressing sustainability issues such as climate change, biodiversity loss, livelihoods, poverty, policy, land use change, water, and social and environmental justice (Fig. 6). Our change point analysis shows notable inflection points around 1990 and 2000, years that follow calls to address global Earth system changes and move toward "sustainable development of the Biosphere" (Clarke and Munn 1986, Keeble 1988). The smaller upsurge post-2010 can likely be attributed to the integration of SES with broader sustainability initiatives (Herrero-Jáuregui et al. 2018), such as the Sustainable Development Goals (SDGs), the Future Earth initiative and its core research programs such as the Program on Ecosystem Change and Society (PECS), and the Intergovernmental Platform on Biodiversity and Ecosystem Services (IPBES)

A strong integration of SES research with societal issues (Turner et al. 2016) affirms calls for the development of stronger sciencesociety interfaces (Fischer et al. 2015, Tengö et al. 2017) to guide research, knowledge cocreation, and decision making (Turner et al. 2016). However, as many researchers have recognized, taking a knowledge coproduction approach to understanding SES and supporting policy and decision making can be demanding. Aside from the time required to establish relationships with knowledge partners, particularly when operating in transdisciplinary teams that seek evidence from multiple knowledge platforms (Tengö et al. 2014, 2017), challenges also arise from the inherent methodological pluralism that characterizes the SES research field (Turner et al. 2016, Herrero-Jáuregui et al. 2018, Preiser 2018). Furthermore, if we accept that seeking evidence from multiple knowledge traditions (Tengö et al. 2014, Díaz et al. $2015 a, b)$ represents a more ethical approach to understanding SES, we have to be cognizant of the fact that much of our current academic knowledge for understanding SES has been generated in the Global North (also see Herrero-Jáuregui et al. 2018). This 
highlights a more general need for developing academic voices from the global south.

\section{Many different methods from a variety of disciplines inform SES research}

That methods from many different disciplines are used in SES research is perhaps intuitive, but our study provides a strong empirical validation of this statement, and by virtue of our typology, an accessible overview of the kinds of methods that are used in the field. Our study identified 311 methods (reduced from an initial list of 632) that we grouped into 27 categories, or types, of methods that are commonly used in SES research, providing empirical support for the notion of methodological pluralism in SES research.

Within the place-based studies that we analyzed, we found that spatial mapping and analysis, historical profiling and reconstruction, interviews, and futures analysis were most commonly used (Fig. 7). The use of these methods may be partly driven by the most common SES research topics, including policy, trade, conservation, adaptation, and land use change (Fig. 6b) because they are the most common methods we found to be used to investigate these topics (Table 3). Interestingly, interviews and participatory data collection were much more commonly used than ecological field data collection (Fig. 7), but this may because ecological field data collection methods are often not articulated in the abstracts of, for example, papers that assess land use change. Economic and other decision-support methods were also quite widely used, including impact analysis, livelihood and vulnerability analysis, and decision analysis. This provides further support for the importance of the increasing emphasis on the science-policy interface and knowledge coproduction in SES research. In contrast, state-and-transition analysis, systems scoping, and games were much more rarely used. These are methods that are particularly well suited to the study of SES (Schultz et al. 2007, Janssen et al. 2010, Provencher et al. 2016, Edwards et al. 2019), but may not have been as well-represented in our dataset on account of their categories containing fewer specific methods, a general limitation of our study.

Our typology of methods spanning different disciplines can provide some orientation to early-career researchers to navigate the methodological pluralism that characterizes the SES field. For new researchers entering the field, a key challenge relates to knowing which methods could be used to investigate a particular SES research question (Haider et al. 2018). Our list of method categories offers researchers a manageable overview of potential tools they might employ in their research, and provides a foundation for scholarly engagement around methodological integration.

\section{Methods used in SES research account for the underlying characteristics of CAS to varying degrees}

To gain deeper insight into the suitability of methods used in SES research in accounting for the CAS nature of SES, the authors used a thought exercise to map the different method typologies onto the six organizing principles of CAS, as identified by Preiser et al. (2018; Table 4). There are obvious limitations to such an approach, most notably that our assessment was limited by the knowledge of the author team about different methods and the contexts in which they are applied. Nevertheless, the exercise yielded several insights that could be explored in future research on the nature of SES research.
A number of the methods highlighted in our review, such as network analysis and agent-based modeling, are particularly well suited to explore relationality in SES (Preiser et al. 2018). Both network analysis and agent-based modeling are used extensively in SES research (Fig. 7), and offer integrative frameworks that capture relations and connectivity, can help to develop rich pictures, and deal with heterogeneity and redundancy (Janssen et al. 2006, Bodin and Crona 2009, An 2012, Filatova et al. 2013). Agent-based modeling and network analysis are processorientated models that rely on decentralized control and automata to detect and create emergent patterns, and so do well to account for the adaptive and self-generating organizational capacities of CAS.

Generally, the methods used in SES research have been sensitive to the context-dependency of SES challenges, probably helped by the notion that SES research has emerged from place-based localscale studies (Colding and Barthel 2019). Many methods used in anticipatory future studies are adept at adapting frameworks to context, and specifically focus on anticipating adaptation and change (Berkhout et al. 2002, Carpenter et al. 2006, Shaw et al. 2009, Sheppard et al. 2011). These methods, and other participatory research methods that gather multiple evidencebased knowledge (Tengö et al. 2014) can help with observerdependent framing (Shirk et al. 2012)

Although there are a reasonable number of methods that can account for the dynamic interactions that constitute complex systems and their relations with the environment, it may be difficult to find the necessary data to conduct analyses over sufficient time spans. Nevertheless, in fields such as system and dynamic modeling, there is a notable tradition of developing models that incorporate feedback loops, i.e., account for slow and fast variables (e.g., Levin et al. 2013, Lade and Niiranen 2017), nonlinearity, and unpredictability. Lade and Niiranen (2017) have proposed generalized modeling to be a particularly promising tool in both participatory and research settings to develop processbased understanding of SES dynamics despite limited system knowledge, but acknowledge that there are challenges to overcome. Similarly, Levin et al. (2013) show how essential features of SES have been successfully introduced into optimal management models (particularly in grasslands and coral reefs) and highlight strategies, like modeling fast and slow variables separately where possible, that can improve the suitability of dynamic models to the realities of SES as CAS.

There is mixed evidence for how good current methods are at coping with the radical openness of SES. Although participatory research, which can help with observer-dependent framing (Shirk et al. 2012), is common, as are a host of other methods that gather multiple evidence-based knowledge (Tengö et al. 2014), few methods can truly account for unknown variables that could have important influences on model behavior. Stochastic modeling methods, and research conducted at multiple scales, however, offer promising avenues.

Complex causality seems to be the organizing principle of CAS that methods struggle the most to address. To account for the nonlinearity of cause-and-effect trajectories and contend with emergence and the nature of wicked problems, we need methods that are able to collect large volumes of data, sense-making methods that can explore the implication of different trajectories, and methods that trace causality across scales. Although methods 
such as participatory narrative enquiry and dialogue workshops can help highlight nonlinear and cross-scale relationships, understanding how these relationships drive cause and effect or bring about emergent patterns of behavior is an exceedingly more complex and data-intensive task (Levin et al. 2013).

\section{CONCLUSION}

In this paper we review several dimensions of the growth of the SES research field, most notably describing it by the methods used in empirical SES research. Methodological pluralism remains one of the biggest challenges in conducting SES research. Our categorized list provides a manageable overview of common methods used in SES research that can serve as a guide to new researchers entering the field, and a first step to more methodological transparency. Our list also offers an opportunity for this field to assess its development into the future, particularly in terms of methodological integration. Assessing methods through the lens of SES as CAS offers a first, if limited, perspective on the alignment between the theory and philosophy that underpins SES research and methods used in the field. More empirical assessments are needed on the suitability of different methods for understanding different elements of CAS in SES research, and it would be interesting to see research on the development of new methods to fill identified gaps. Last, this paper focuses on methods used in SES, but the way in which research is combined in different contexts is perhaps what makes the field most interesting. We hope that future researchers will build on our work to investigate the way in which methods are combined in practice, for different purposes, and on the ethical and ontological contexts that shape our questions and approaches.

\section{Responses to this article can be read online at: http://www.ecologyandsociety.org/issues/responses. php/11236}

\section{Acknowledgments:}

The authors would like to thank A. Norström, M. Nyström, G. Peterson, M. Schlüter, and M. Tengö for their contribution to refining method categories, and for providing feedback on an early draft of the manuscript. This work is supported by the Guidance for Resilience in the Anthropocene: Investments for Development (GRAID) project funded by the Swedish International Development Agency (SIDA) hosted at Stockholm Resilience Centre, Sweden. Reinette Biggs is also supported by the South African Research Chairs Initiative (SARChI) of the Department of Science and Technology and National Research Foundation of South Africa (grant 98766); and a Young Researchers Grant from the Vetenskapsrådet in Sweden (grant 621-2014-5137).

\section{LITERATURE CITED}

An, L. 2012. Modeling human decisions in coupled human and natural systems: review of agent-based models. Ecological Modelling 229:25-36. https://doi.org/10.1016/j.ecolmodel.2011.07.010

Anderies, J. M., C. Folke, B. Walker, and E. Ostrom. 2013. Aligning key concepts for global change policy: robustness, resilience, and sustainability. Ecology and Society 18(2):8. https:// doi.org/10.5751/ES-05178-180208

Anderies, J. M., M. A. Janssen, and E. Ostrom. 2004. A framework to analyze the robustness of social-ecological systems from an institutional perspective. Ecology and Society $9(1): 18$. https://doi. org/10.5751/ES-00610-090118

Angelstam, P., K. Andersson, M. Annerstedt, R. Axelsson, M. Elbakidze, P. Garrido, P. Grahn, K. I. Jönsson, S. Pedersen, P. Schlyter, E. Skärbäck, M. Smith, and I. Stjernquist. 2013. Solving problems in social-ecological systems: definition, practice and barriers of transdisciplinary research. Ambio 42(2):254-265. https://doi.org/10.1007/s13280-012-0372-4

Becker, E. 2012. Social-ecological systems as epistemic objects. Pages 37-59 in M. Glaser, G. Krause, B. M. W. Ratter, and M. Welp, editors. Human-nature interactions in the Anthropocene: potentials of social-ecological systems analysis. Routledge, London, UK. https://doi.org/10.4324/9780203123195

Berkes, F., J. Colding, and C. Folke. 2003. Navigating socialecological systems: building resilience for complexity and change. Cambridge University Press, Cambridge, UK. https://doi. org/10.1017/cbo9780511541957

Berkhout, F., J. Hertin, and A. Jordan. 2002. Socio-economic futures in climate change impact assessment: using scenarios as 'learning machines.' Global Environmental Change 12(2):83-95. https://doi.org/10.1016/S0959-3780(02)00006-7

Binder, C. R., J. Hinkel, P. W. G. Bots, and C. Pahl-Wostl. 2013. Comparison of frameworks for analyzing social-ecological systems. Ecology and Society 18(4):26. https://doi.org/10.5751/ ES-05551-180426

Bodin, Ö., and B. I. Crona. 2009. The role of social networks in natural resource governance: What relational patterns make a difference? Global Environmental Change 19(3):366-374. https:// doi.org/10.1016/j.gloenvcha.2009.05.002

Bodin, Ö., and M. Tengö. 2012. Disentangling intangible socialecological systems. Global Environmental Change 22(2):430-439. https://doi.org/10.1016/j.gloenvcha.2012.01.005

Bots, P. W. G., M. Schlüter, and J. Sendzimir. 2015. A framework for analyzing, comparing, and diagnosing social-ecological systems. Ecology and Society 20(4):18. https://doi.org/10.5751/ ES-08051-200418

Brandt, P., A. Ernst, F. Gralla, C. Luederitz, D. J. Lang, J. Newig, F. Reinert, D. J. Abson, and H. von Wehrden. 2013. A review of transdisciplinary research in sustainability science. Ecological Economics 92:1-15. https://doi.org/10.1016/j.ecolecon.2013.04.008

Capstick, S., L. Whitmarsh, W. Poortinga, N. Pidgeon, and P. Upham. 2015. International trends in public perceptions of climate change over the past quarter century. Wiley Interdisciplinary Reviews: Climate Change 6(4):435-435. https:// doi.org/10.1002/wcc.343

Carpenter, S. R., E. M. Bennett, and G. D. Peterson. 2006. Scenarios for ecosystem services: an overview. Ecology and Society 11(1):29. https://doi.org/10.5751/ES-01610-110129

Carpenter, S. R., C. Folke, A. Norström, O. Olsson, L. Schultz, B. Agarwal, P. Balvanera, B. Campbell, J. C. Castilla, W. Cramer, 
R. DeFries, P. Eyzaguirre, T. P. Hughes, S. Polasky, Z. Sanusi, R. Scholes, and M. Spierenburg. 2012. Program on ecosystem change and society: an international research strategy for integrated social-ecological systems. Current Opinion in Environmental Sustainability 4(1):134-138. https://doi.org/10.1016/j.cosust.2012.01.001

Clarke, W. C., and R. E. Munn. 1986. Sustainable development of the biosphere. Cambridge University Press, Cambridge, UK.

Colding, J., and S. Barthel. 2019. Exploring the social-ecological systems discourse 20 years later. Ecology and Society 24(1):2. https://doi.org/10.5751/es-10598-240102

Collins, S. L., S. R. Carpenter, S. M. Swinton, D. E. Orenstein, D. L. Childers, T. L. Gragson, N. B. Grimm, J. M. Grove, S. L. Harlan, J. P. Kaye, A. K. Knapp, G. P. Kofinas, J. J. Magnuson, W. H. McDowell, J. M. Melack, L. A. Ogden, G. P. Robertson, M. D. Smith, and A. C. Whitmer. 2011. An integrated conceptual framework for long-term social-ecological research. Frontiers in Ecology and the Environment 9(6):351-357. https://doi. org/10.1890/100068

Cumming, G. S. 2014. Theoretical frameworks for the analysis of social-ecological systems. Pages 3-24 in S. Sakai and C. Umetsu, editors. Social-ecological systems in transition. Springer, Tokyo, Japan. https://doi.org/10.1007/978-4-431-54910-9_1

Díaz, S., S. Demissew, J. Carabias, C. Joly, M. Lonsdale, N. Ash, A. Larigauderie, J. R. Adhikari, S. Arico, A. Báldi, A. Bartuska, I. A. Baste, A. Bilgin, E. Brondizio, K. M. Chan, V. E. Figueroa, A. Duraiappah, M. Fischer, R. Hill, T. Koetz, P. Leadley, P. Lyver, G. M. Mace, B. Martin-Lopez, M. Okumura, D. Pacheco, U. Pascual, E. S. Pérez, B. Reyers, E. Roth, O. Saito, R. J. Scholes, N. Sharma, H. Tallis, R. Thaman, R. Watson, T. Yahara, Z. A. Hamid, C. Akosim, Y. Al-Hafedh, R. Allahverdiyev, E. Amankwah, T. S. Asah, Z. Asfaw, G. Bartus, A. L. Brooks, J. Caillaux, G. Dalle, D. Darnaedi, A. Driver, G. Erpul, P. EscobarEyzaguirre, P. Failler, A. M. M. Fouda, B. Fu, H. Gundimeda, S. Hashimoto, F. Homer, S. Lavorel, G. Lichtenstein, W. A. Mala, W. Mandivenyi, P. Matczak, C. Mbizvo, M. Mehrdadi, J. P. Metzger, J. B. Mikissa, H. Moller, H. A. Mooney, P. Mumby, H. Nagendra, C. Nesshover, A. A. Oteng-Yeboah, G. Pataki, M. Roué, J. Rubis, M. Schultz, P. Smith, R. Sumaila, K. Takeuchi, S. Thomas, M. Verma, Y. Yeo-Chang, D. Zlatanova, S. T. Asah, Z. Asfaw, G. Bartus, L. A. Brooks, J. Caillaux, G. Dalle, D. Darnaedi, A. Driver, G. Erpul, P. Escobar-Eyzaguirre, P. Failler, A. M. M. Fouda, B. Fu, H. Gundimeda, S. Hashimoto, F. Homer, S. Lavorel, G. Lichtenstein, W. A. Mala, W. Mandivenyi, P. Matczak, C. Mbizvo, M. Mehrdadi, J. P. Metzger, J. B. Mikissa, H. Moller, H. A. Mooney, P. Mumby, H. Nagendra, C. Nesshover, A. A. Oteng-Yeboah, G. Pataki, M. Roué, J. Rubis, M. Schultz, P. Smith, R. Sumaila, K. Takeuchi, S. Thomas, M. Verma, Y. Yeo-Chang, and D. Zlatanova. 2015b. The IPBES conceptual framework connecting nature and people. Current Opinion in Environmental Sustainability 14:1-16. https://doi.org/10.1016/j.cosust.2014.11.002

Díaz, S., S. Demissew, C. Joly, W. M. Lonsdale, and A. Larigauderie. 2015a. A Rosetta Stone for nature's benefits to people. PLoS Biology 13(1):e1002040. https://doi.org/10.1371/ journal.pbio. 1002040

Díaz, S., J. Fargione, F. S. Chapin III, and D. Tilman. 2006. Biodiversity loss threatens human well-being. PLoS Biology 4(8): e277. https://doi.org/10.1371/journal.pbio.0040277
Droste, N., D. D'Amato, and J. J. Goddard. 2018. Where communities intermingle, diversity grows - the evolution of topics in ecosystem service research. PLOS ONE 13(9):e0204749. https:// doi.org/10.1371/journal.pone.0204749

Edwards, P., L. Sharma-Wallace, A. Wreford, L. Holt, S. Flood, N. A. Cradock-Henry, and S. J. Velarde. 2019. Tools for adaptive governance for complex social-ecological systems: a review of role-playing-games as serious games at the community-policy interface. Environmental Research Letters. https://doi. org/10.1088/1748-9326/ab4036

Environmental Systems Research Institute (ESRI). 2017. ArcGIS Desktop. ESRI, Redlands, California, USA.

Filatova, T., P. H. Verburg, D. C. Parker, and C. A. Stannard. 2013. Spatial agent-based models for socio-ecological systems: challenges and prospects. Environmental Modelling \& Software 45:1-7. https://doi.org/10.1016/j.envsoft.2013.03.017

Fischer, J., T. A. Gardner, E. M. Bennett, P. Balvanera, R. Biggs, S. Carpenter, T. Daw, C. Folke, R. Hill, T. P. Hughes, T. Luthe, M. Maass, M. Meacham, A. V. Norström, G. Peterson, C. Queiroz, R. Seppelt, M. Spierenburg, and J. Tenhunen. 2015. Advancing sustainability through mainstreaming a socialecological systems perspective. Current Opinion in Environmental Sustainability 14:144-149. https://doi.org/10.1016/j.cosust.2015.06.002

Folke, C. 2006. Resilience: the emergence of a perspective for social-ecological systems analyses. Global Environmental Change 16(3):253-267. https://doi.org/10.1016/j.gloenvcha.2006.04.002

Folke, C., and F. Berkes. 1998. Understanding dynamics of ecosystem-institution linkages for building resilience. Beijer Discussion Paper No. 112. The Beijer Institute of Ecological Economics, Royal Academy of Sciences, Stockholm, Sweden.

Folke, C., R. Biggs, A. V. Norström, B. Reyers, and J. Rockström. 2016. Social-ecological resilience and biosphere-based sustainability science. Ecology and Society 21(3):41. https://doi.org/10.5751/ ES-08748-210341

Gough, D., S. Oliver, and J. Thomas. 2012. An introduction to systematic reviews. SAGE, Thousand Oaks, California, USA.

Guo, H., S. Weingart, and K. Börner. 2011. Mixed-indicators model for identifying emerging research areas. Scientometrics 89 (1):421-435. https://doi.org/10.1007/s11192-011-0433-7

Haider, L. J., J. Hentati-Sundberg, M. Giusti, J. Goodness, M. Hamann, V. A. Masterson, M. Meacham, A. Merrie, D. Ospina, C. Schill, and H. Sinare. 2018. The undisciplinary journey: earlycareer perspectives in sustainability science. Sustainability Science 13(1):191-204. https://doi.org/10.1007/s11625-017-0445-1

Herrero-Jáuregui, C., C. Arnaiz-Schmitz, M. F. Reyes, M. Telesnicki, I. Agramonte, M. H. Easdale, M. F. Schmitz, M. Aguiar, A. Gómez-Sal, and C. Montes. 2018. What do we talk about when we talk about social-ecological systems? A literature review. Sustainability 10(8):2950. https://doi.org/10.3390/su10082950

Hertz, T., and M. Schlüter. 2015. The SES-framework as boundary object to address theory orientation in social-ecological system research: the SES-TheOr approach. Ecological Economics 116:12-24. https://doi.org/10.1016/j.ecolecon.2015.03.022 
Janssen, M. A., Ö. Bodin, J. M. Anderies, T. Elmqvist, H. Ernstson, R. R. J. McAllister, P. Olsson, and P. Ryan. 2006. Toward a network perspective on the resilience of socialecological systems. Ecology and Society 11(1):15. https://doi. org/10.5751/ES-01462-110115

Janssen, M. A., R. Holahan, A. Lee, and E. Ostrom. 2010. Lab experiments for the study of social-ecological systems. Science 328(5978):613-617. https://doi.org/10.1126/science.1183532

Keeble, B. R. 1988. The Brundtland report: 'Our common future. 'Medicine and War 4(1):17-25. https://doi.org/10.1080/0748800$\underline{8808408783}$

Lade, S. J., and S. Niiranen. 2017. Generalized modeling of empirical social-ecological systems. Natural Resource Modeling 30(3):e12129. https://doi.org/10.1111/nrm.12129

Lee, P. M. 2012. Bayesian statistics: an introduction. John Wiley and Sons, Chichester, UK.

Levin, S., T. Xepapadeas, A.-S. Crépin, J. Norberg, A. de Zeeuw, C. Folke, T. Hughes, K. Arrow, S. Barrett, G. Daily, P. Ehrlich, N. Kautsky, K.-G. Mäler, S. Polasky, M. Troell, J. R. Vincent, and B. Walker. 2013. Social-ecological systems as complex adaptive systems: modeling and policy implications. Environment and Development Economics 18(02):111-132. https://doi.org/10.1017/ $\underline{\mathrm{S} 1355770 \mathrm{X} 12000460}$

Liu, J., T. Dietz, S. R. Carpenter, M. Alberti, C. Folke, E. Moran, A. N. Pell, P. Deadman, T. Kratz, J. Lubchenco, E. Ostrom, Z. Ouyang, W. Provencher, C. L. Redman, S. H. Schneider, and W. W. Taylor. 2007b. Complexity of coupled human and natural systems. Science 317(5844):1513-1516. https://doi.org/10.1126/ science. 1144004

Liu, J., T. Dietz, S. R. Carpenter, C. Folke, M. Alberti, C. L. Redman, S. H. Schneider, E. Ostrom, A. N. Pell, J. Lubchenco, W. W. Taylor, Z. Ouyang, P. Deadman, T. Kratz, and W. Provencher. 2007a. Coupled human and natural systems. Ambio 36(8):639-649. https://doi.org/10.1579/0044-7447(2007)36[639: chans]2.0.co:2

Magliocca, N. R., E. C. Ellis, G. R. H. Allington, A. de Bremond, J. Dell'Angelo, O. Mertz, P. Messerli, P. Meyfroidt, R. Seppelt, and P. H. Verburg. 2018. Closing global knowledge gaps: producing generalized knowledge from case studies of socialecological systems. Global Environmental Change 50:1-14. https:// doi.org/10.1016/j.gloenvcha.2018.03.003

Norberg, J., and G. S. Cumming. 2008. Complexity theory for a sustainable future. Columbia University Press, New York, New York, USA.

Ostrom, E. 2007. A diagnostic approach for going beyond panaceas. Proceedings of the National Academy of Sciences 104 (39):15181-15187. https://doi.org/10.1073/pnas.0702288104

Ostrom, E. 2009. A general framework for analyzing sustainability of social-ecological systems. Science 325 (5939):419-422. https://doi.org/10.1126/science.1172133

Pahl-Wostl, C., C. Giupponi, K. Richards, C. Binder, A. de Sherbinin, D. Sprinz, T. Toonen, and C. van Bers. 2013. Transition towards a new global change science: requirements for methodologies, methods, data and knowledge. Environmental Science \& Policy 28:36-47. https://doi.org/10.1016/j.envsci.2012.11.009
Parker, J. N., and E. J. Hackett. 2012. Hot spots and hot moments in scientific collaborations and social movements. American Sociological Review 77(1):21-44. https://doi.org/10.1177/0003122411433763

Partelow, S. 2018. A review of the social-ecological systems framework: applications, methods, modifications, and challenges. Ecology and Society 23(4):36. https://doi.org/10.5751/ES-10594-230436

Petticrew, M., and H. Roberts. 2006. Systematic reviews in the social sciences: a practical guide. John Wiley \& Sons, Hoboken, New Jersey, USA.

Preiser, R. 2018. Key features of complex adaptive systems: practical implications for guiding actions. Centre for Complex Adaptive Systems, Stellenbosch University, South Africa.

Preiser, R., R. Biggs, A. De Vos, and C. Folke. 2018. Socialecological systems as complex adaptive systems: organizing principles for advancing research methods and approaches. Ecology and Society 23(4):46. https://doi.org/10.5751/ES-10558-230446

Provencher, L., L. Frid, C. Czembor, and J. T. Morisette. 2016. State-and-transition models: conceptual versus simulation perspectives, usefulness and breadth of use, and land management applications. Pages 371-407 in M. J. Germino, J. C. Chambers, and C. S. Brown, editors. Exotic brome-grasses in arid and semiarid ecosystems of the western U.S.: causes, consequences, and management implications. Springer, Cham, Switzerland. https:// doi.org/10.1007/978-3-319-24930-8 13

Pullin, A. S., and T. M. Knight. 2009. Doing more good than harm - building an evidence-base for conservation and environmental management. Biological Conservation 142 (5):931-934. https://doi.org/10.1016/j.biocon.2009.01.010

Pullin, A. S., and G. B. Stewart. 2006. Guidelines for systematic review in conservation and environmental management. Conservation Biology 20(6):1647-1656. https://doi.org/10.1111/ j.1523-1739.2006.00485.x

Rockström, J. 2016. Future Earth. Science 351(6271):319. https:// doi.org/10.1126/science.aaf2138

Rockström, J., W. Steffen, K. Noone, Å. Persson, F. S. Chapin III, E. F. Lambin, T. M. Lenton, M. Scheffer, C. Folke, H. J. Schellnhuber, B. Nykvist, C. A. de Wit, T. Hughes, S. van der Leeuw, H. Rodhe, S. Sörlin, P. K. Snyder, R. Costanza, U. Svedin, M. Falkenmark, L. Karlberg, R. W. Corell, V. J. Fabry, J. Hansen, B. Walker, D. Liverman, K. Richardson, P. Crutzen, and J. A. Foley. 2009. A safe operating space for humanity. Nature 461 (7263):472-475. https://doi.org/10.1038/461472a

Rodríguez-Pose, A. 2006. Is there an 'Anglo-American' domination in human geography? And, is it bad? Environment and Planning A: Economy and Space 38(4):603-610. https://doi. org/10.1068/a38280

Rogers, K. H., R. Luton, H. Biggs, R. Biggs, S. Blignaut, A. G. Choles, C. G. Palmer, and P. Tangwe. 2013. Fostering complexity thinking in action research for change in social-ecological systems. Ecology and Society 18(2):31. https://doi.org/10.5751/es-05330-180231

Schlüter, M., L. J. Haider, S. J. Lade, E. Lindkvist, R. Martin, K. Orach, N. Wijermans, and C. Folke. 2019. Capturing emergent phenomena in social-ecological systems: an analytical 
framework. Ecology and Society 24(3):11. https://doi. org/10.5751/ES-11012-240311

Schlüter, M., R. R. J. McAllister, R. Arlinghaus, N. Bunnefeld, K. Eisenack, F. Hölker, E. J. Milner-Gulland, B. Müller, E. Nicholson, M. Quaas, and M. Stöven. 2012. New horizons for managing the environment: a review of coupled social-ecological systems modeling. Natural Resource Modeling 25(1):219-272. https://doi.org/10.1111/j.1939-7445.2011.00108.x

Schultz, L., C. Folke, and P. Olsson. 2007. Enhancing ecosystem management through social-ecological inventories: lessons from Kristianstads Vattenrike, Sweden. Environmental Conservation 34 (2):140-152. https://doi.org/10.1017/S0376892907003876

Shaw, A., S. Sheppard, S. Burch, D. Flanders, A. Wiek, J. Carmichael, J. Robinson, and S. Cohen. 2009. Making local futures tangible: synthesizing, downscaling, and visualizing climate change scenarios for participatory capacity building. Global Environmental Change 19(4):447-463. https://doi. org/10.1016/j.gloenvcha.2009.04.002

Sheppard, S. R. J., A. Shaw, D. Flanders, S. Burch, A. Wiek, J. Carmichael, J. Robinson, and S. Cohen. 2011. Future visioning of local climate change: a framework for community engagement and planning with scenarios and visualisation. Futures 43 (4):400-412. https://doi.org/10.1016/j.futures.2011.01.009

Shirk, J. L., H. L. Ballard, C. C. Wilderman, T. Phillips, A. Wiggins, R. Jordan, E. McCallie, M. Minarchek, B. V. Lewenstein, M. E. Krasny, and R. Bonney. 2012. Public participation in scientific research: a framework for deliberate design. Ecology and Society 17(2):29. https://doi.org/10.5751/ ES-04705-170229

Steffen, W., Å. Persson, L. Deutsch, J. Zalasiewicz, M. Williams, K. Richardson, C. Crumley, P. Crutzen, C. Folke, L. Gordon, M. Molina, V. Ramanathan, J. Rockström, M. Scheffer, H. J. Schellnhuber, and U. Svedin. 2011. The Anthropocene: from global change to planetary stewardship. Ambio 40(7):739-761. https://doi.org/10.1007/s13280-011-0185-x

Stirling, A. 2015. Developing 'nexus capabilities': towards transdisciplinary methodologies. SPRU Discussion Paper. Science Policy Research Unit, Brighton, UK.

Summers, J. K., L. M. Smith, J. L. Case, and R. A. Linthurst. 2012. A review of the elements of human well-being with an emphasis on the contribution of ecosystem services. Ambio 41 (4):327-340. https://doi.org/10.1007/s13280-012-0256-7

Tengö, M., E. S. Brondizio, T. Elmqvist, P. Malmer, and M. Spierenburg. 2014. Connecting diverse knowledge systems for enhanced ecosystem governance: the multiple evidence base approach. Ambio 43(5):579-591. https://doi.org/10.1007/ $\underline{\text { s13280-014-0501-3 }}$

Tengö, M., R. Hill, P. Malmer, C. M. Raymond, M. Spierenburg, F. Danielsen, T. Elmqvist, and C. Folke. 2017. Weaving knowledge systems in IPBES, CBD and beyond-lessons learned for sustainability. Current Opinion in Environmental Sustainability 26-27:17-25. https://doi.org/10.1016/j.cosust.2016.12.005

Thorne, S., L. Jensen, M. H. Kearney, G. Noblit, and M. Sandelowski. 2004. Qualitative metasynthesis: reflections on methodological orientation and ideological agenda. Qualitative Health Research 14(10):1342-1365. https://doi.org/10.1177/1049$\underline{732304269888}$

Trimble, M. J., and R. J. van Aarde. 2012. Geographical and taxonomic biases in research on biodiversity in human-modified landscapes. Ecosphere 3(12):1-16. https://doi.org/10.1890/ ES12-00299.1

Turner II, B. L., K. J. Esler, P. Bridgewater, J. Tewksbury, N. Sitas, B. Abrahams, F. S. Chapin III, R. R. Chowdhury, P. Christie, S. Diaz, P. Firth, C. N. Knapp, J. Kramer, R. Leemans, M. Palmer, D. Pietri, J. Pittman, J. Sarukhán, R. Shackleton, R. Seidler, and B. van Wilgen. 2016. Socio-environmental systems (SES) research: What have we learned and how can we use this information in future research programs. Current Opinion in Environmental Sustainability 19:160-168. https://doi.org/10.1016/ j.cosust.2016.04.001

Turner II, B. L., R. E. Kasperson, P. A. Matson, J. J. McCarthy, R. W. Corell, L. Christensen, N. Eckley, J. X. Kasperson, A. Luers, M. L. Martello, C. Polsky, A. Pulsipher, and A. Schiller. 2003. A framework for vulnerability analysis in sustainability science. Proceedings of the National Academy of Sciences of the United States of America 100(14):8074-8079. https://doi.org/10.1073/ pnas. 1231335100

Wagner, C. S., J. D. Roessner, K. Bobb, J. T. Klein, K. W. Boyack, J. Keyton, I. Rafols, and K. Börner. 2011. Approaches to understanding and measuring interdisciplinary scientific research (IDR): a review of the literature. Journal of Informetrics 5 (1):14-26. https://doi.org/10.1016/j.joi.2010.06.004

Walker, B. H., L. H. Gunderson, A. Kinzig, C. Folke, S. R. Carpenter, and L. Schultz. 2006. A handful of heuristics and some propositions for understanding resilience in social-ecological systems. Ecology and Society 11(1):13. https://doi.org/10.5751/ ES-01530-110113

Wu, J. 2013. Landscape sustainability science: ecosystem services and human well-being in changing landscapes. Landscape Ecology 28(6):999-1023. https://doi.org/10.1007/s10980-013-9894-9 
Appendix 1. Search query string used to conduct a systematic review in Scopus on 15 July 2015

( TITLE-ABS-KEY ( "Social-Ecological" ) OR TITLE-ABS-KEY ( "HumanEnvironment*") OR TITLE-ABS-KEY ("Affective Ecolog*") OR TITLE-ABS-KEY ( "Man-Environment* relation*" ) OR TITLE-ABS-KEY ("Social-Environmental" ) OR TITLE-ABS-KEY ( "Socio-Environmental" ) OR TITLE-ABS-KEY ( "Socio-Ecological) OR TITLE-ABS-KEY ( "Eco-social" ) OR TITLE-ABS-KEY ( "Human-environment relation*" ) OR TITLE-ABS-KEY ( "Human-Nature relation*") OR TITLE-ABS-KEY ( "Nature-society relation*" ) OR TITLE-ABS-KEY ( "Coupled Human*" ) OR TITLE-ABSKEY ( "Coupled Human*") ) AND ( LIMIT-TO ( DOCTYPE , "ar") OR LIMIT-TO ( DOCTYPE, "re" ) OR LIMIT-TO ( DOCTYPE, "ch") OR LIMIT-TO ( DOCTYPE, "ip" ) ) AND ( LIMIT-TO ( SUBJAREA, "ENVI" ) OR LIMIT-TO ( SUBJAREA, "SOCI" ) OR LIMIT-TO ( SUBJAREA, "AGRI" ) OR LIMIT-TO ( SUBJAREA, "EART" ) OR LIMIT-TO ( SUBJAREA, "ECON" ) OR LIMIT-TO ( SUBJAREA, "ARTS") OR LIMIT-TO ( SUBJAREA, "ENER" ) OR LIMIT-TO ( SUBJAREA, "MULT" ) OR LIMIT-TO ( SUBJAREA, "DECI") ) AND ( EXCLUDE ( SUBJAREA, "MEDI") OR EXCLUDE ( SUBJAREA, "ARTS")) AND ( EXCLUDE ( SUBJAREA, "ENGI" ) OR EXCLUDE ( SUBJAREA, "PSYC")) AND ( EXCLUDE ( SUBJAREA, "BIOC" ) OR EXCLUDE ( SUBJAREA, "COMP") OR EXCLUDE ( SUBJAREA, "CENG") OR EXCLUDE ( SUBJAREA, "PHAR") OR EXCLUDE ( SUBJAREA, "CHEM") OR EXCLUDE ( SUBJAREA, "VETE") OR EXCLUDE ( SUBJAREA, "MATH") OR EXCLUDE ( SUBJAREA, "IMMU") OR EXCLUDE ( SUBJAREA, "NURS") OR EXCLUDE ( SUBJAREA, "HEAL") OR EXCLUDE ( SUBJAREA, "NEUR" ) OR EXCLUDE ( SUBJAREA, "MATE" ) OR EXCLUDE ( SUBJAREA, "PHYS") ) AND ( EXCLUDE ( SRCTYPE, "d") OR EXCLUDE ( SRCTYPE, "p" ) ) AND ( LIMIT-TO ( LANGUAGE, "English") ) 
Appendix 2. Methods Identified in the systematic review are shown in an Excel spreadsheet. The spreadsheet shows the 632 methods originally identified, and a reduced list of 311 methods (categorized here as "analytical methods", "data collection methods",

"planning methods", and "representation and communication". The spreadsheet also lists methods from the original list that were excluded, as well as "methods" that were removed because they were considered to be "approaches" rather than "methods". 
Appendix 3. Key terms that were identified in a word cloud analysis. Terms that were included, excluded, and combined with other terms in the final analysis are noted.

Table 3.1. List of the top 100 terms as extracted from author-provided keywords in 2198 place-based studies on social-ecological systems, published between before July 2015.

\section{Rank Concatenated Term Frequency Inclusion}

1 socialecologicalsystems

2 resilience

3 climatechange

4 sustainability

5 ecosystemservices

6 sustainabledevelopment

7 governance

8 socialecologicalsystem

9 vulnerability

10 environment

11 adaptation

12 biodiversity

13 adaptivemanagement

14 agriculture

15 institutions

16 conservation

17 china

18 adaptivecapacity

\section{Excluded}

272 Included

168 Included

168 Combined with "Sustainable Development"

124 Included

113 Included

89 Combined with "Institutions"

85 Included

84 Included

83 Included

77 Combined with "Adaptive capacity, adaptive management"

73 Included

64 Combined with "Adaptive capacity, adaptive management"

60 Included

57 Combined with "Governance"

56 Combined with "Protected Areas"

53 Excluded

51 Combined with "adaption", "adaptive management" 
19 landuse

20 deforestation

21 politicalecology

22 trade

23 fisheries

24 landusechange

25 naturalresourcemanagement

26 complexity

27 humanenvironmentinteractions

28 gis

29 scale

30 socialecologicalresilience

31 australia

32 commonpoolresources

33 comanagement

34 development

35 brazil

36 landdegradation

37 management

38 participation

39 uncertainty
49 Combine with "Land use change", "Land Cover Change", "Degredation"

46 Included

44 Included

44 Included

43 Included

43 Included

42 Included

41 Excluded

38 Excluded

37 Excluded

37 Excluded

33 Excluded

32 Excluded

32 Included

31 Combined with "Institutions" \& "Governance"

31 Combined with "Sustainable Development"

29 Excluded

29 Combined with "land use change"

28 Combined with "natural resource management"

28 Excluded

28 Excluded 
40 globalization

41 india

42 sociallearning

43 environmentalpolicy

44 internationaltrade

45 mexico

46 ecology

47 landscape

48 policy

49 remotesensing

50 risk

51 adaptivegovernance

52 africa

53 environmentaleducation

54 globalchange

55 industrialecology

56 socialecological

57 decisionmaking

58 environmentalchange

59 environmentaljustice

60 foodsecurity

61 smallscalefisheries

62 developingcountries
27 Excluded

27 Excluded

27 Excluded

26 Combined with "policy"

26 Excluded

26 Excluded

25 Excluded

25 Excluded

25 Combined with "environmentalpolicy"

25 Excluded

25 Excluded

24 Excluded

24 Excluded

24 Excluded

24 Excluded

24 Excluded

24 Excluded

23 Excluded

23 Excluded

23 Combined with "Social Justice" (not shown)

23 Combine with "Food"

23 Combined with "Fisheries"

22 Excluded 
63 ecosystembasedmanagement

64 environmentalgovernance

65 fisheriesmanagement

66 humanenvironmentinteraction

67 livelihoods

68 socialcapital

69 collectiveaction

70 ecosystemmanagement

71 indicators

72 irrigation

73 tourism

74 archaeology

75 biodiversityconservation

76 collaboration

77 marineprotectedareas

78 traditionalecologicalknowledge

79 transformation

80 adaptivecycle

81 desertification

82 drought

83 environmentalmanagement

84 interdisciplinary
22 Combined with "natural resource management" and "management"

22 Combined with "Instiutions", "Governance"

22 Combined with "Fisheries"

22 Included

22 Included

22 Excluded

21 Excluded

21 Excluded

21 Excluded

20 Excluded

20 Excluded

19 Excluded

19 Combined with "Conservation" and "Protected Areas"

19 Excluded

19 Combined with "Conservation" and "Protected Areas"

19 Excluded

19 Excluded

18 Excluded

18 Excluded

18 Combined with "Desertification"

18 Combined with "Natural Reseoource Management"

18 Excluded 

85 modeling
18 Excluded
86 southafrica
18 Excluded
87 urban
18 Included
88 watermanagement
18 Combined with "water"
89 economics
17 Excluded
90 learning
17 Excluded
91 nature
17 Excluded
92 poverty
17 Included
93 protectedareas
17 Combined with "Conservation"
94 scenarios
17 Excluded
95 environmentaldegradation
16 Combined with "degradation"
96 holocene
16 Excluded
97 invasivespecies
16 Excluded
98 latinamerica
16 Excluded
99 agentbasedmodeling
15 Excluded
100 aquaculture
15 Exclusion 
Appendix 4. Author assessment of method categories ability to account for the underlying principles of complex adaptive systems, denoted by an " $x$ ". The "justification" column explains the authors' reasoning for each score.

Please click here to download file 'appendix4.xlsx'. 